Supporting Information for

\title{
Semiquantitative Visual Chiral Assay with a Pseudoenantiomeric Fluorescent Sensor Pair
}

Yu Chen, ${ }^{\text {a }}$ Feng Zhao, ${ }^{\text {a }}$ Jun Tian, ${ }^{\text {a Le Jiang, }}$ $\mathrm{Yu}^{* a}$, Xiaoqi $\mathrm{Yu}^{\mathrm{a}}$ and $\mathrm{Lin} \mathrm{Pu}^{* \mathrm{~b}}$

\section{Table of Content}

1. NMR and HRMS Spectra of Compounds $(R)-5$ and (S)-5 S2

2. Fluorescence spectra of $\mathbf{5}$ with methionine S5

3. Visual quantification of the enantiomeric composition of methionine. .S9

4. Fluorescence spectra of $(R)-5$ with amino acids

5. Visual quantification of the enantiomeric composition of amino acids S17

5.1 Visual quantification of the enantiomeric composition of histidine

5.2 Visual quantification of the enantiomeric composition of asparagine S18

5.3 Visual quantification of the enantiomeric composition of argnine S19

5.4 Visual quantification of the enantiomeric composition of glutamine S21

5.5 Visual quantification of the enantiomeric composition of lysine. S20

5.6 Visual quantification of the enantiomeric composition of phenylalanine S23

5.7 Visual quantification of the enantiomeric composition of tryptophane. S25

6. UV-Vis spectra, NMR and Mass spectroscopic studies of the reactions. S27 


\section{NMR and HRMS Spectra of Compounds $(R)-5$ and $(S)-5$}

${ }^{1} \mathrm{H}$ NMR (400 MHz) spectra of $(R)-5$ in DMSO-d 6

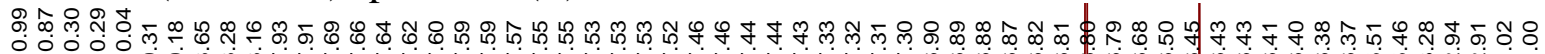

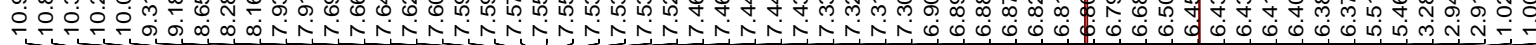

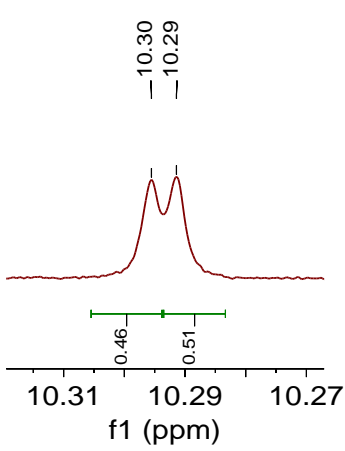

$\mathrm{NaO}_{3} \mathrm{~S}$<smiles>CCN(CC)c1ccc2c(c1)OC(c1ccc(N(C)C)cc1)=CC21c2ccccc2C(=O)N1Cc1cc2cc([N+]([O-])(O)O[Na])ccc2c(C)c1O</smiles>

$\mathrm{f1}(\mathrm{ppm})$

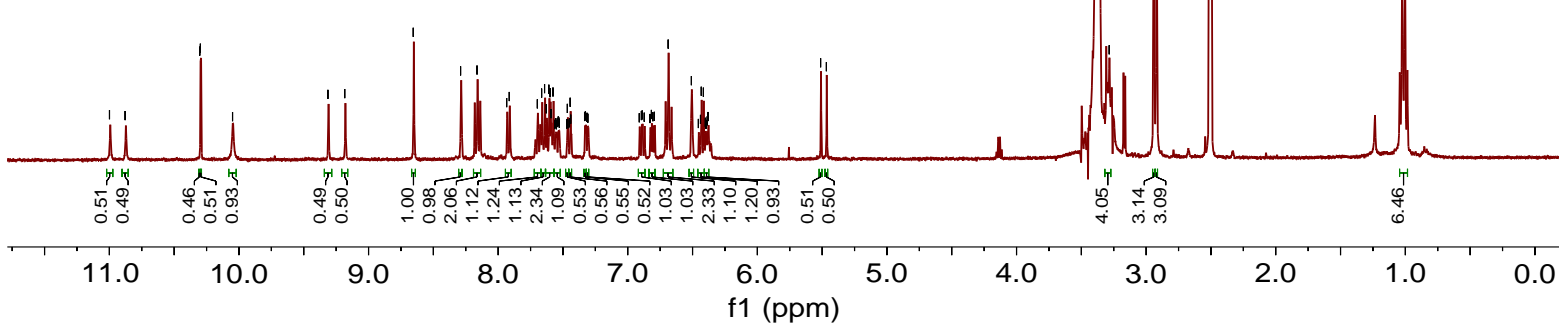

${ }^{13} \mathrm{C}\left\{{ }^{1} \mathrm{H}\right\}$ NMR (201 MHz) spectra of $(R)-5$ in DMSO-d 6

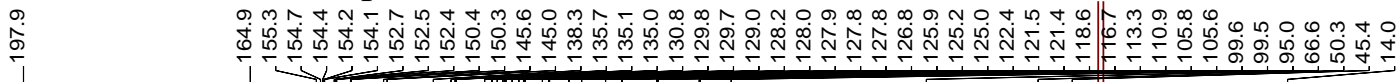

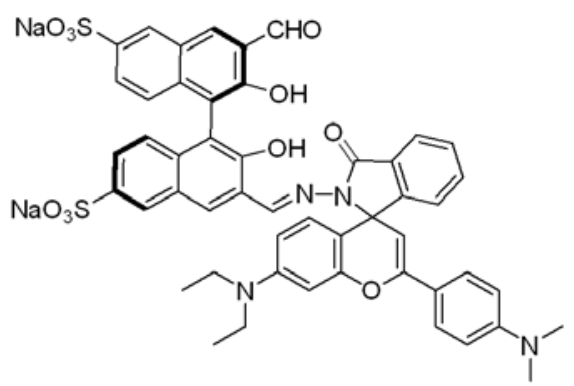

$\begin{array}{llllllllllllllllllllll}210 & 200 & 190 & 180 & 170 & 160 & 150 & 140 & 130 & 120 & 110 & 100 & 90 & 80 & 70 & 60 & 50 & 40 & 30 & 20 & 10 & 0\end{array}$ f1 (ppm) 
HRMS of $(R)-5$

ESI+

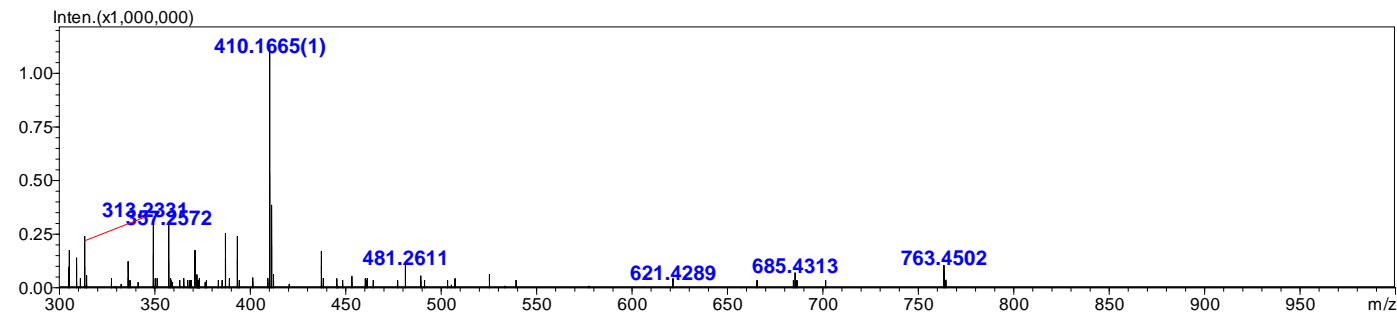

ESI-

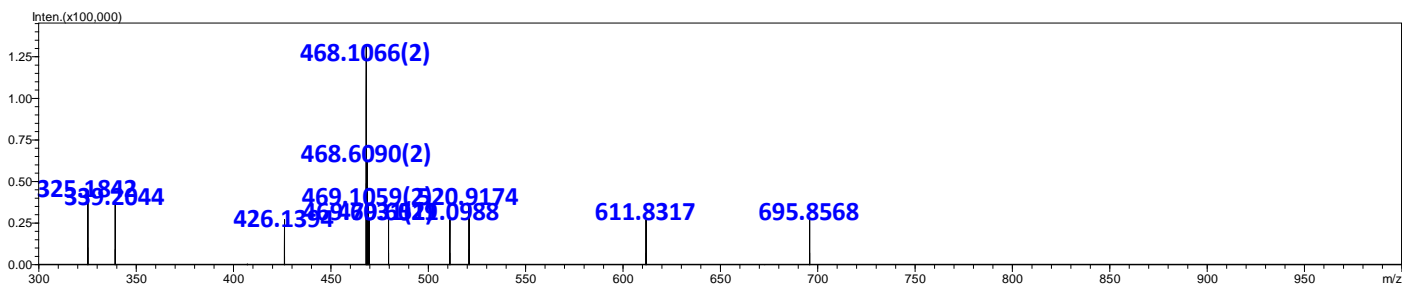

${ }^{1} \mathrm{H}$ NMR (400MHz) spectra of (S)-5 in DMSO- $\mathrm{d}_{6}$

等
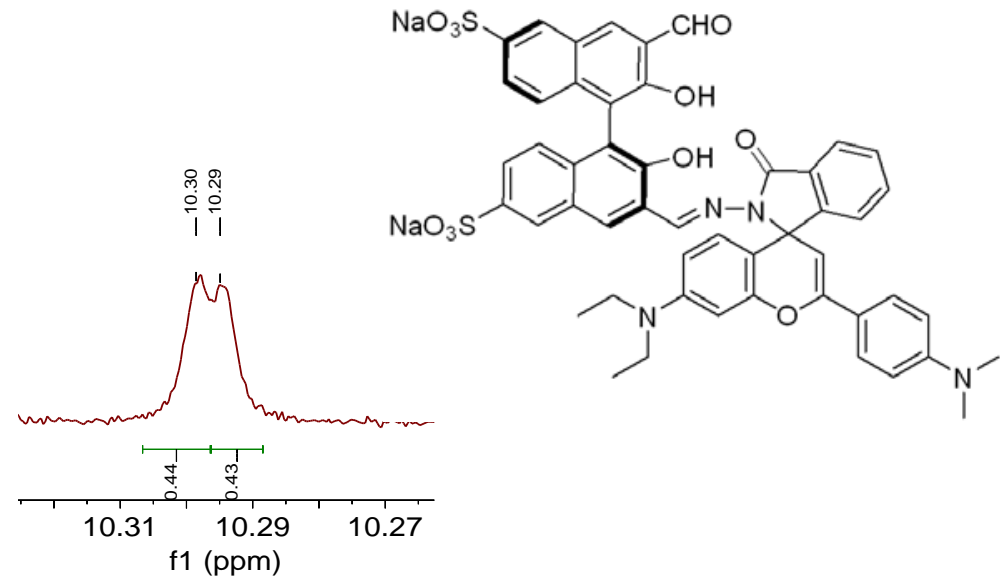

$$
\text { f1 (ppm) }
$$

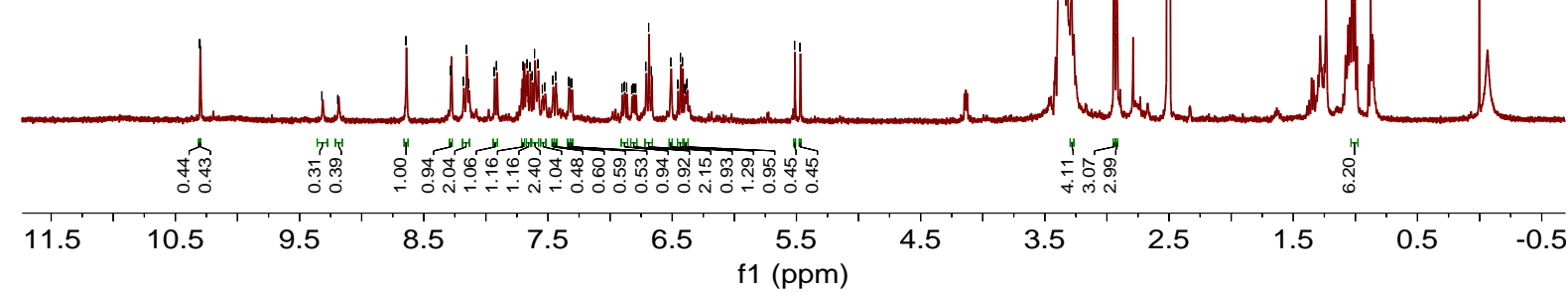


${ }^{13} \mathrm{C}\left\{{ }^{1} \mathrm{H}\right\}$ NMR (201 MHz) spectra of $(S)-5$ in DMSO- $d_{6}$

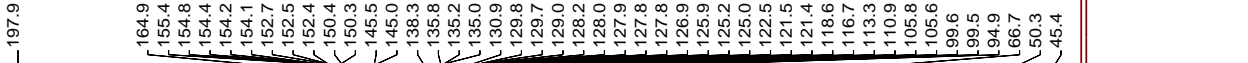

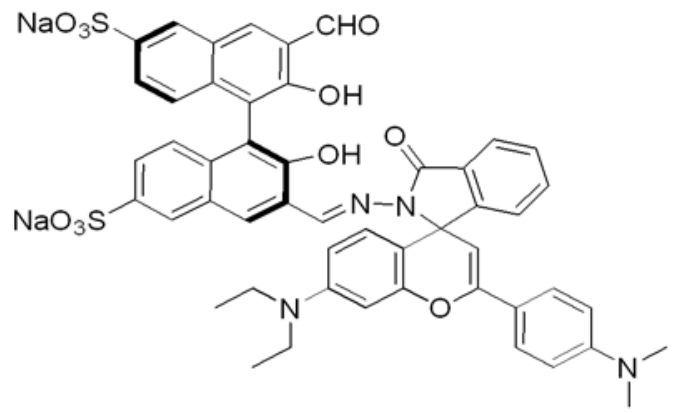

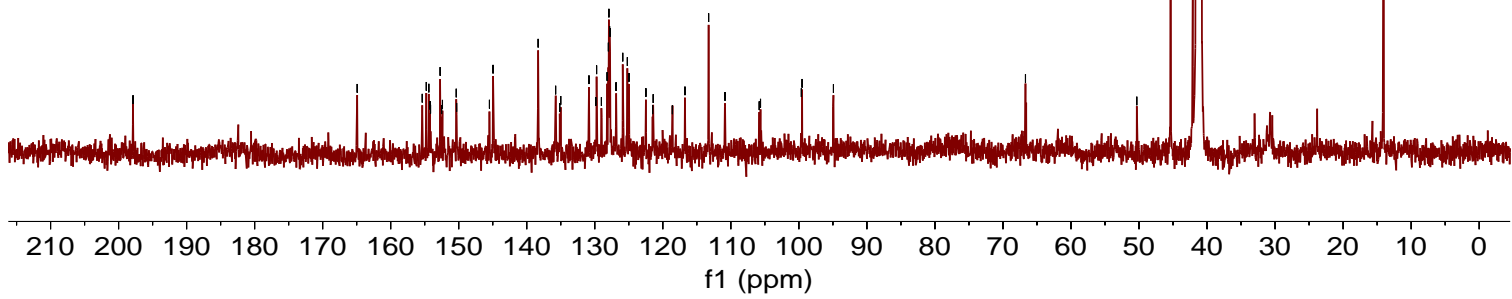

HRMS of (S)-5

ESI+

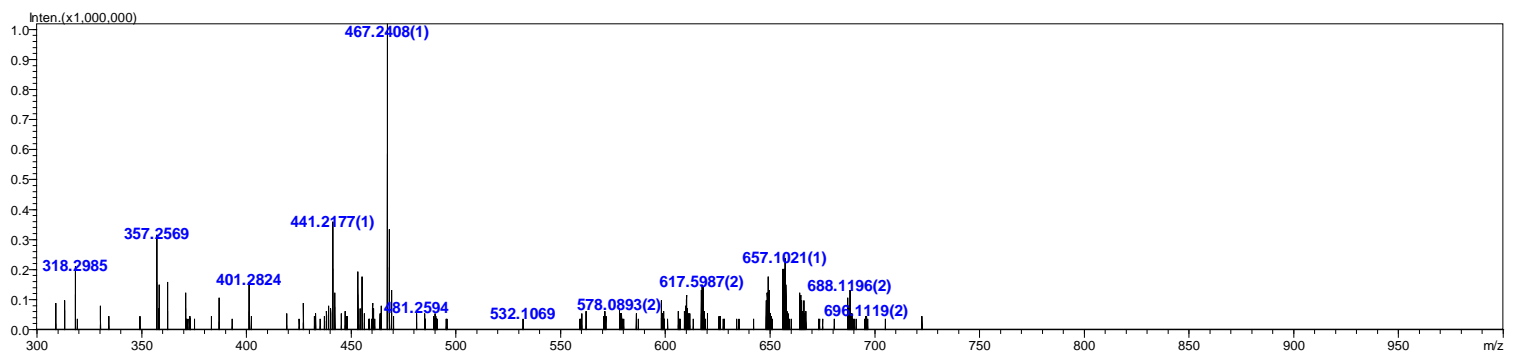

ESI-

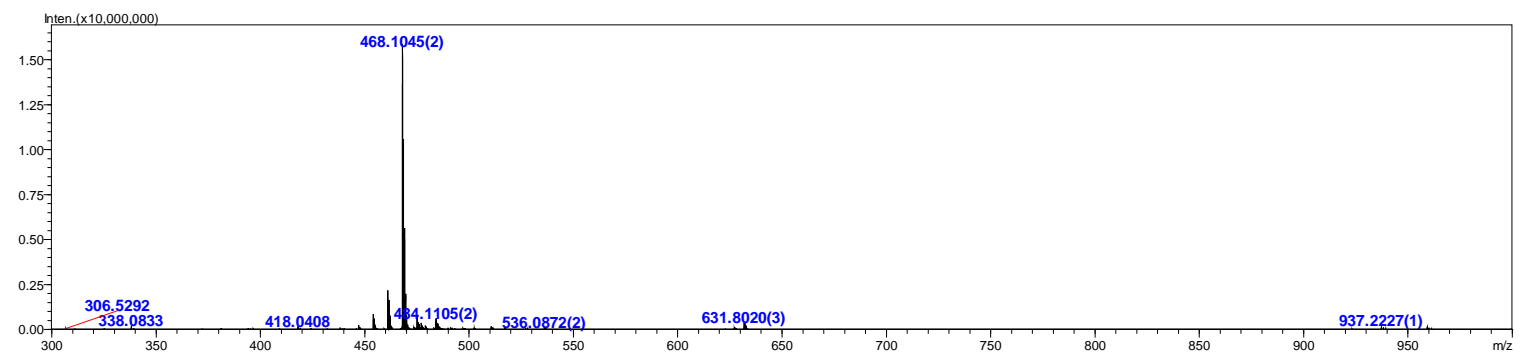


Figure S1. Structures of amino acids studied.<smiles>CC(N)C(=O)O</smiles>

Ala<smiles>N=C(N)NCCCC(N)C(=O)O</smiles>

$\operatorname{Arg}$<smiles>NC(=O)CC(N)C(=O)O</smiles>

Asn<smiles>N[C](CC(=O)O)C(=O)O</smiles>

Asp<smiles>NC(Cc1c[nH]cn1)C(=O)O</smiles><smiles>CCC(C)C(N)C(=O)O</smiles>

Ile<smiles>N[C](Cc1ccccc1)C(=O)O</smiles>

Phe<smiles>NC(Cc1c[nH]c2ccccc12)C(=O)O</smiles><smiles>O=C(O)C1CCCN1</smiles><smiles>CC(C)C(N)C(=O)O</smiles><smiles>NC(CS)C(=O)O</smiles>

Cys<smiles>CC(C)CC(N)C(=O)O</smiles>

Leu<smiles>NC(CO)C(=O)O</smiles>

Ser<smiles>CC(O)C(N)C(=O)O</smiles>

$\mathrm{Thr}$

\section{Fluorescence spectra of 5 with methionine}

Figure S2. Fluorescence spectra of $(R)-5(20 \mu \mathrm{M})$ with various equiv of $\mathrm{Zn}^{2+}$ in $50 \mathrm{mM}$ HEPES buffer $(\mathrm{pH}=7.4) / 1 \%$ DMSO in the presence of 100 equiv of D-Met or L-Met. Fluorescence intensity at $655 \mathrm{~nm}$ versus the equiv of $\mathrm{Zn}(\mathrm{OAc})_{2}$. The fluorescence spectra were recorded at room temperature after mixing for $3 \mathrm{~h}(\lambda \operatorname{exc}=420 \mathrm{~nm}$, slits:5/5 nm).
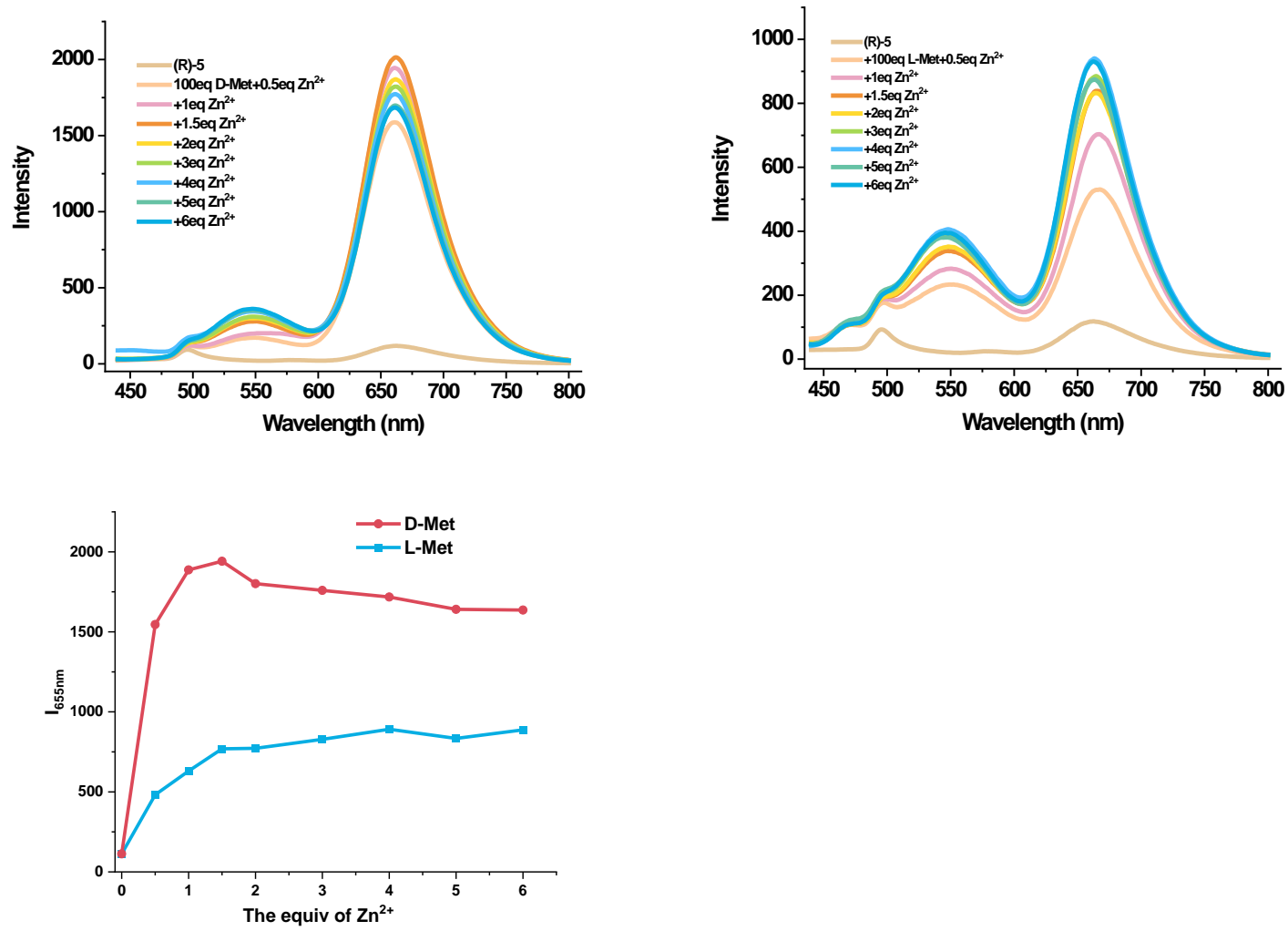
Figure S3. Fluorescence intensity versus time for the reaction of $(R)-5(20 \mu \mathrm{M})$ and $\mathrm{Zn}(\mathrm{OAc})_{2}$ (2 equiv) with D- or L-Met (100 equiv) at room temperature in $50 \mathrm{mM}$ HEPES buffer $(\mathrm{pH}=7.4) / 1 \%$ DMSO. The fluorescence spectra were recorded at room temperature after mixing for various time ( $\lambda$ exc $=420 \mathrm{~nm}$, slits:5/5 nm).
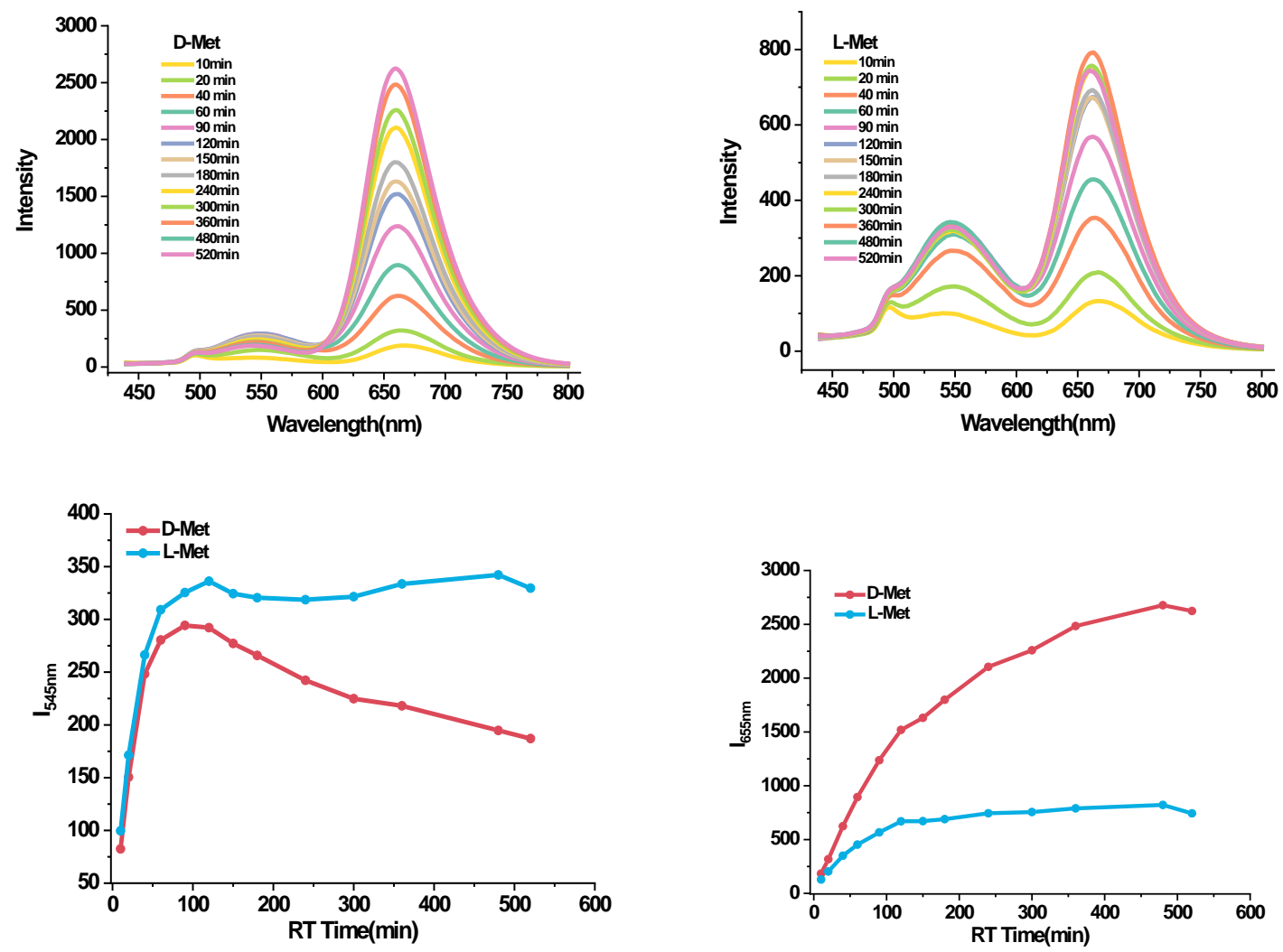

Figure S4. Fluorescence intensity versus ice bath time after $(R)-5+\mathrm{Zn}^{2+}$ (2 equiv) $(20 \mu \mathrm{M})$ with 100 equiv of D-Met or L-Met for $3 \mathrm{~h}$ in $50 \mathrm{mM}$ HEPES $(\mathrm{pH}=7.4) / 1 \%$ DMSO. The fluorescence spectra were recorded at $5{ }^{\circ} \mathrm{C}$ after mixing at room temperature for $3 \mathrm{~h}$ and then chilled in an ice bath for various time ( $\lambda$ exc $=420 \mathrm{~nm}$, slits:5/5 nm).
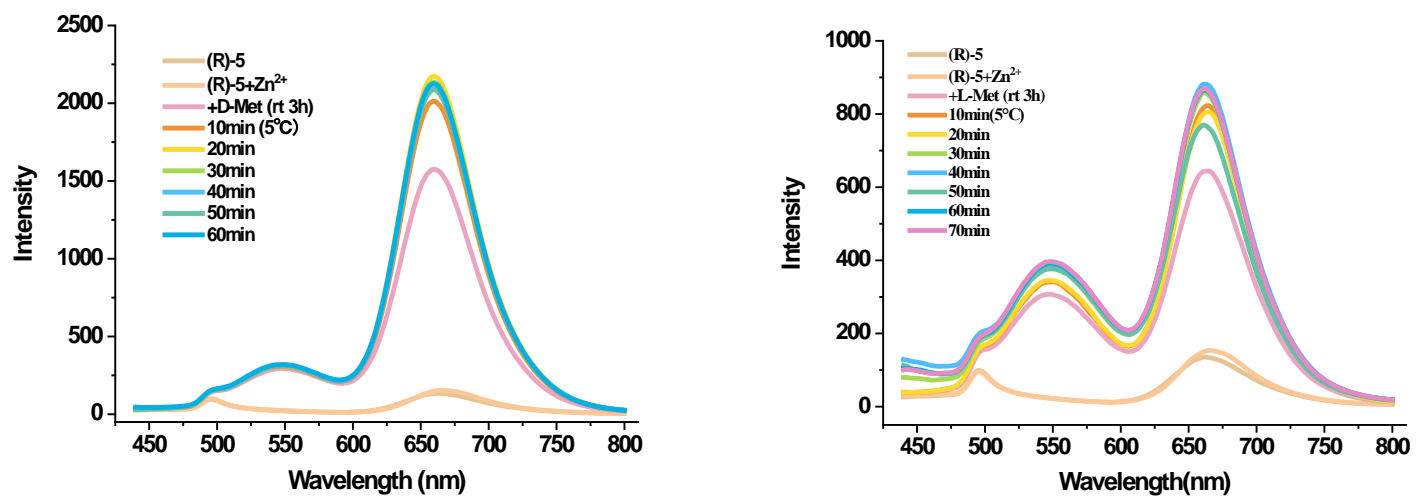


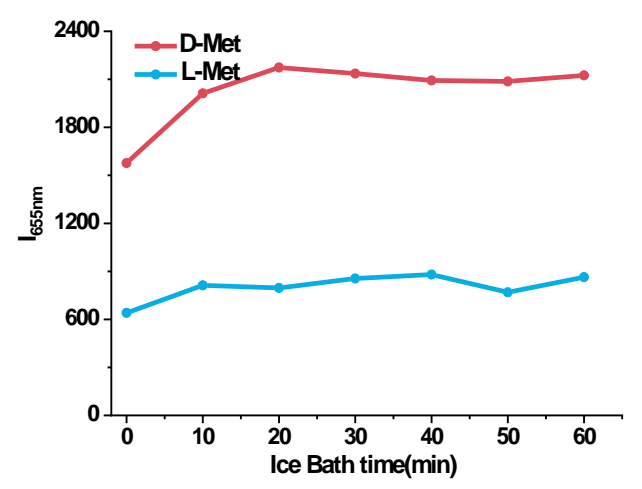

Figure S5. Fluorescence spectra of $(R)-5+\mathrm{Zn}^{2+}$ (2 equiv) $(20 \mu \mathrm{M})$ with various equiv of DMet or L-Met in $50 \mathrm{mM}$ HEPES $(\mathrm{pH}=7.4) / 1 \%$ DMSO. Fluorescence intensity at $655 \mathrm{~nm}$ versus the equiv of methionine. The fluorescence spectra were recorded at $5{ }^{\circ} \mathrm{C}$ after mixing at room temperature for $3 \mathrm{~h}$ and then chilled in an ice bath for $30 \mathrm{~min}(\lambda \mathrm{exc}=420 \mathrm{~nm}$, slits:5/5 $\mathrm{nm})$.
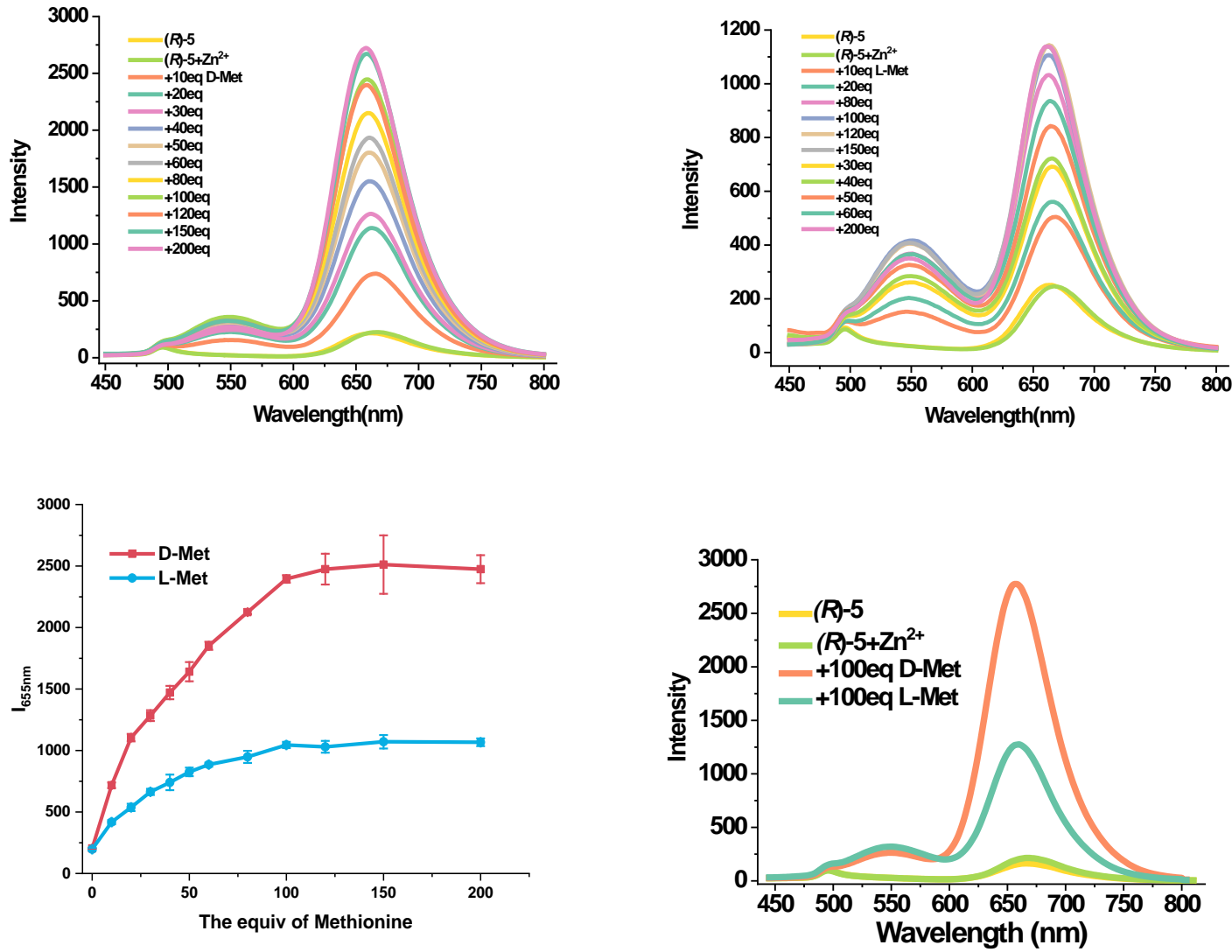
Figure S6. Fluorescence spectra of $(S)-5+\mathrm{Zn}^{2+}$ (2 equiv) $(20 \mu \mathrm{M})$ with various equiv of DMet or L-Met in $50 \mathrm{mM}$ HEPES $(\mathrm{pH}=7.4) / 1 \%$ DMSO. Fluorescence intensity at $655 \mathrm{~nm}$ versus the equiv of methionine. The fluorescence spectra were recorded at $5{ }^{\circ} \mathrm{C}$ after mixing at room temperature for $3 \mathrm{~h}$ and then chilled in an ice bath for $30 \min (\lambda$ exc $=420 \mathrm{~nm}$, slits:5/5 $\mathrm{nm})$.
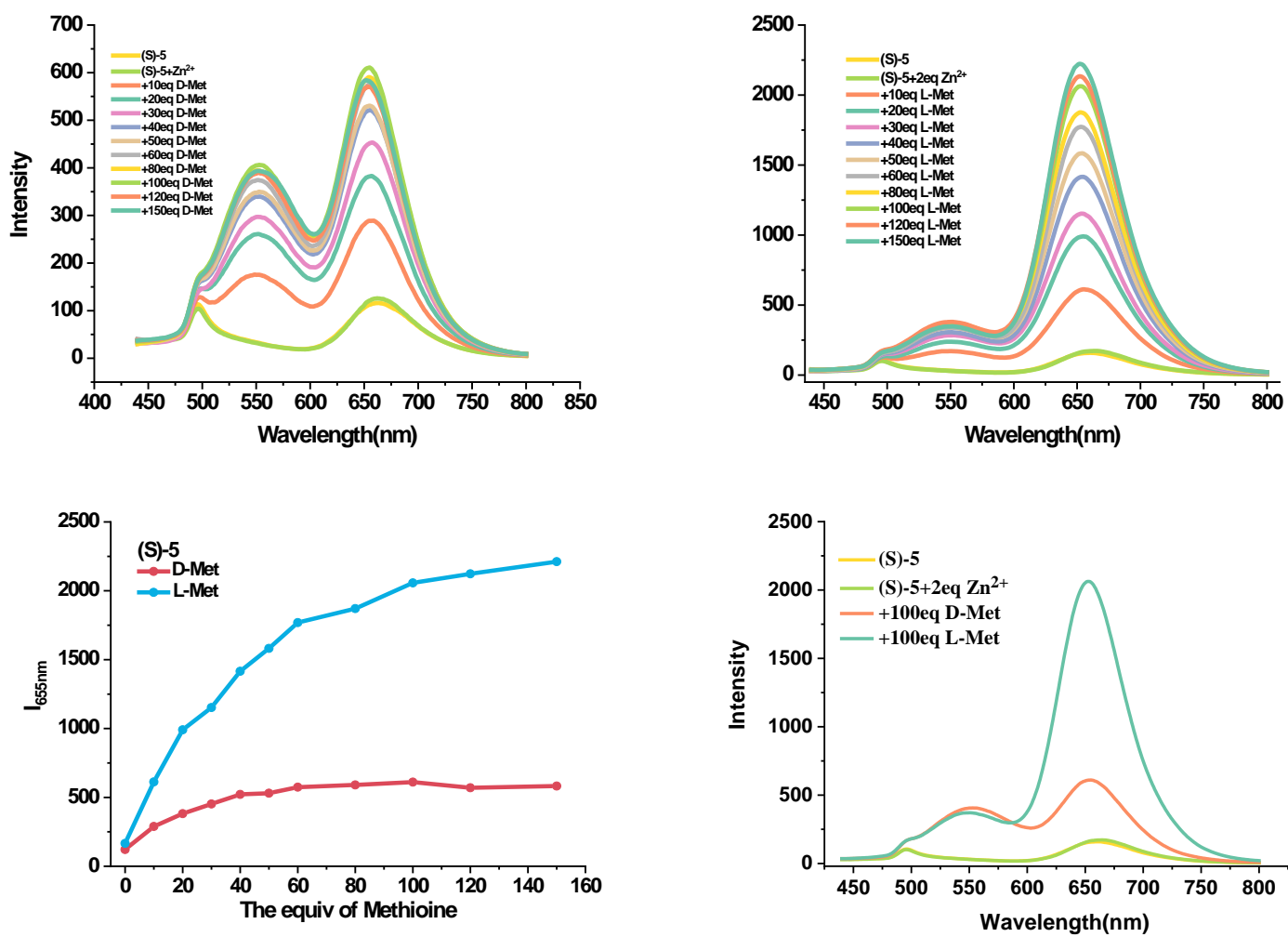

Figure S7. Fluorescence spectra of $(R)-5$ and $(S)-5+\mathrm{Zn}^{2+}$ (2 equiv) $\left(2.0 \times 10^{-5} \mathrm{M}\right.$ in HEPES $/ 1 \%$ DMSO) in the presence of the enantiomeric mixture of methionine (100 equiv). Fluorescence intensity at $655 \mathrm{~nm}$ versus the enantiomeric purity of methionine. The fluorescence spectra were recorded at $5{ }^{\circ} \mathrm{C}$ after mixing at room temperature for $3 \mathrm{~h}$ and then chilled in an ice bath for $30 \mathrm{~min}(\lambda \mathrm{exc}=420 \mathrm{~nm}$, slits:5/5 nm).
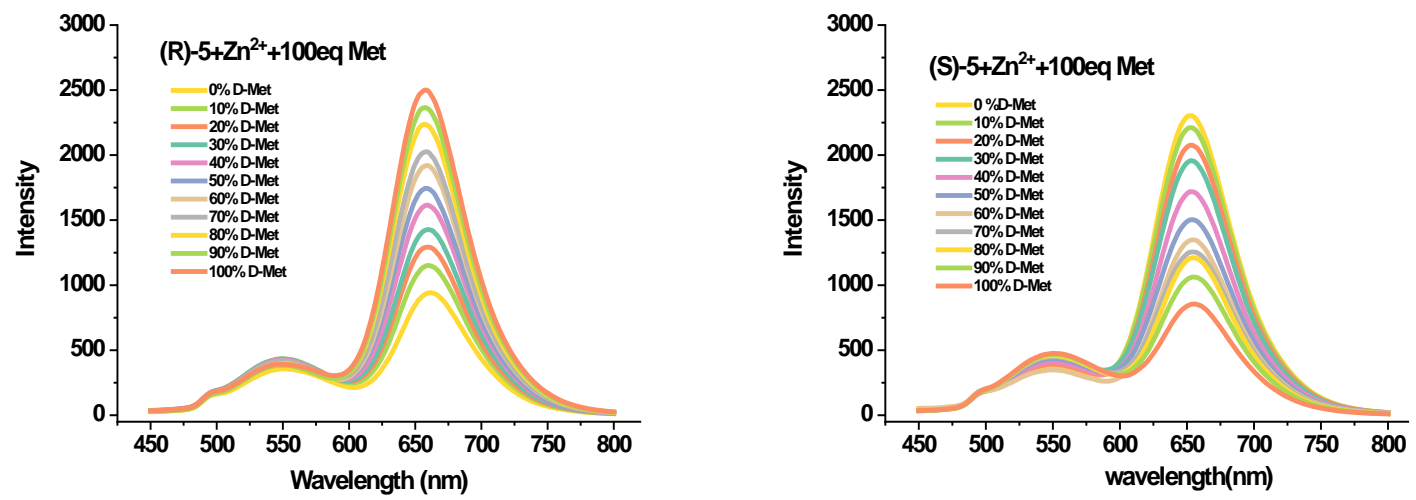


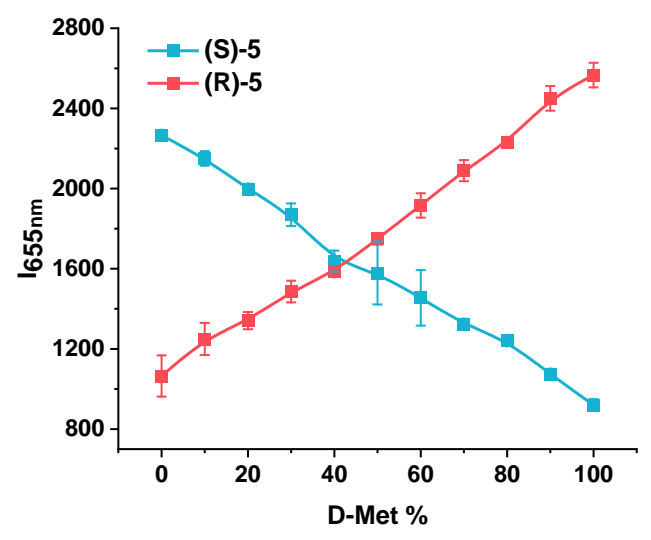

\section{Visual quantification of the enantiomeric composition of methionine}

Figure S8. The fluorescence spectra and visualization tests of $(R)-\mathbf{5}+(S)-\mathbf{4}$ (at various ratios) $+\mathrm{Zn}^{2+}$ (2 equiv, $40 \mu \mathrm{M}$ ) with 100 equiv D-Met or 100 equiv L-Met in $50 \mathrm{mM}$ HEPES. The fluorescence spectra were recorded at room temperature after mixing for $3 \mathrm{~h}(\lambda \mathrm{exc}=420 \mathrm{~nm}$, slits:5/5 nm).
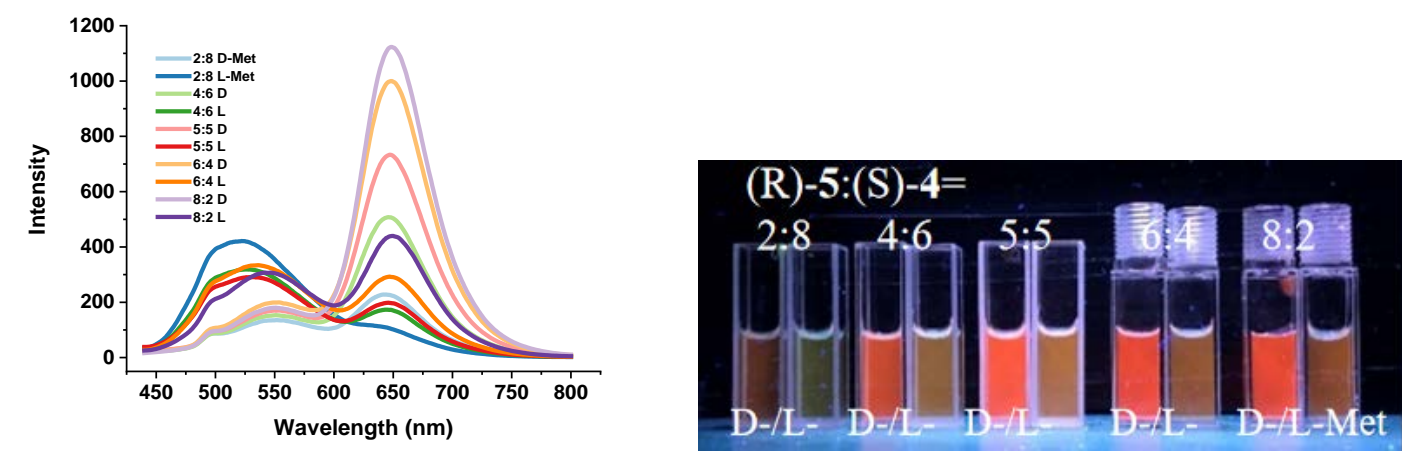

Figure S8(a). ( $R)$-5:(S)-4 = 1:1 $(10 \mu \mathrm{M}+10 \mu \mathrm{M})$. The fluorescence spectra and visualization test of $(R)-5(10 \mu \mathrm{M}$ in DMSO $)+(S)-4(10 \mu \mathrm{M}$ in $\mathrm{MeOH})+\mathrm{Zn}^{2+}(2$ equiv, $40 \mu \mathrm{M})$ with different enantiomeric composition of Met (100 equiv) in $50 \mathrm{mM}$ HEPES. The fluorescence spectra were recorded at room temperature after mixing for $3 \mathrm{~h}(\lambda$ exc $=420 \mathrm{~nm}$, slits:5/5 nm).
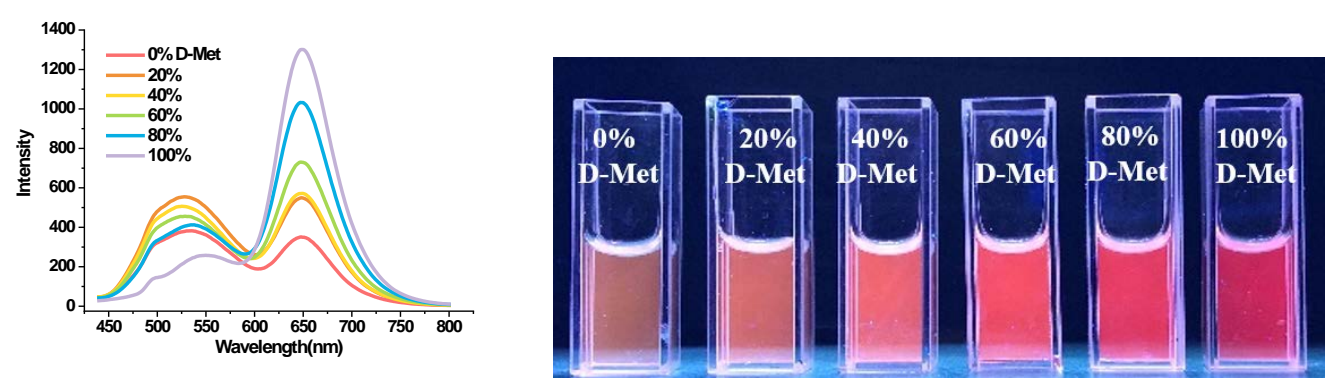
Figure S8(b). $\quad(R)-5:(S)-4=1: 4(4 \mu \mathrm{M}+16 \mu \mathrm{M}) . \quad$ The fluorescence spectra and visualization test of $(R)-5(4 \mu \mathrm{M}$ in DMSO $)+(S)-4(16 \mu \mathrm{M}$ in $\mathrm{MeOH})+\mathrm{Zn}^{2+}(2$ equiv, $40 \mu \mathrm{M})$ with different enantiomeric composition of Met (100 equiv) in $50 \mathrm{mM}$ HEPES. The fluorescence spectra were recorded at room temperature after mixing for $3 \mathrm{~h}(\lambda$ exc $=420 \mathrm{~nm}$, slits:5/5 nm)
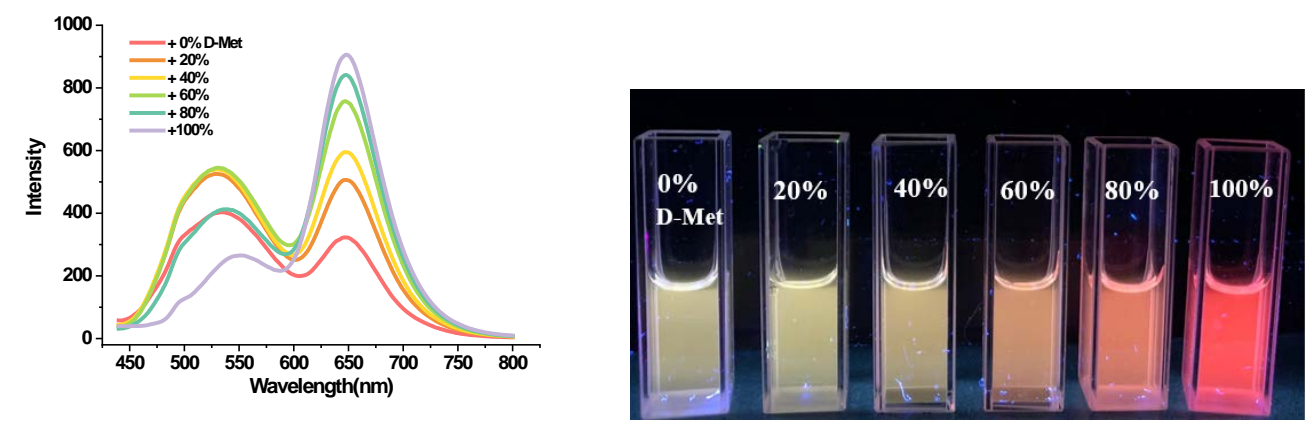

Figure S8(c). $\quad(R)-\mathbf{5 :}(S)-\mathbf{4}=1: 5.7(3 \mu \mathrm{M}+17 \mu \mathrm{M})$. The fluorescence spectra and visualization test of $(R)-5(3 \mu \mathrm{M}$ in DMSO $)+(S)-4(17 \mu \mathrm{M}$ in $\mathrm{MeOH})+\mathrm{Zn}^{2+}$ (2 equiv, $\left.40 \mu \mathrm{M}\right)$ with different enantiomeric composition of Met (100 equiv) in $50 \mathrm{mM} \mathrm{HEPES.} \mathrm{The}$ fluorescence spectra were recorded at room temperature after mixing for $3 \mathrm{~h}(\lambda \mathrm{exc}=420 \mathrm{~nm}$, slits:5/5 nm).
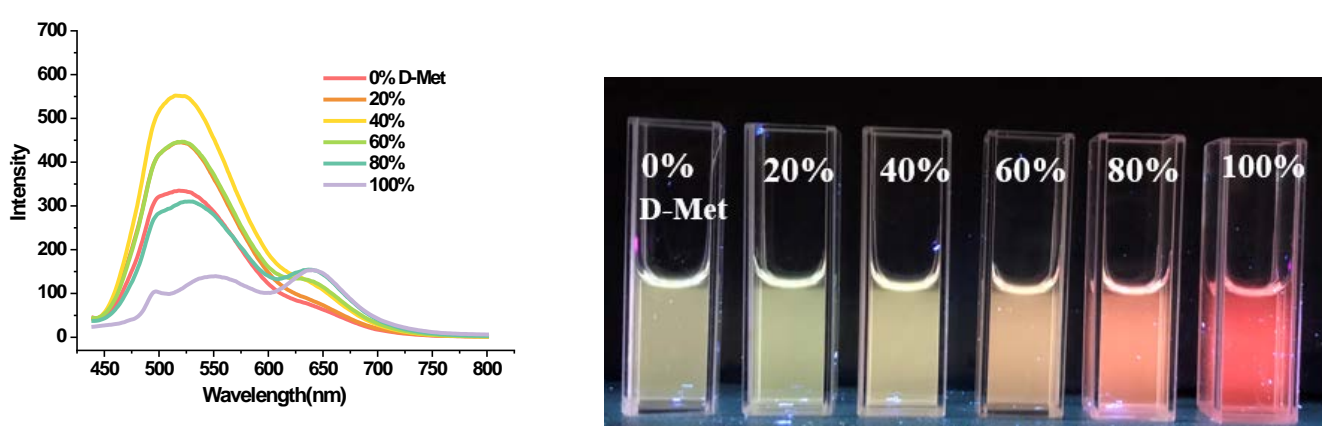

Figure S8(d). $\quad(R)-5:(S)-4=1: 9(2 \mu \mathrm{M}+18 \mu \mathrm{M}) . \quad$ The fluorescence spectra and visualization test of $(R)-5(2 \mu \mathrm{M}$ in DMSO $)+(S)-4(18 \mu \mathrm{M}$ in $\mathrm{MeOH})+\mathrm{Zn}^{2+}(2$ equiv, $40 \mu \mathrm{M})$ with different enantiomeric composition of Met (100 equiv) in $50 \mathrm{mM}$ HEPES. The fluorescence spectra were recorded at room temperature after mixing for $3 \mathrm{~h}(\lambda$ exc $=420 \mathrm{~nm}$, slits:5/5 nm).
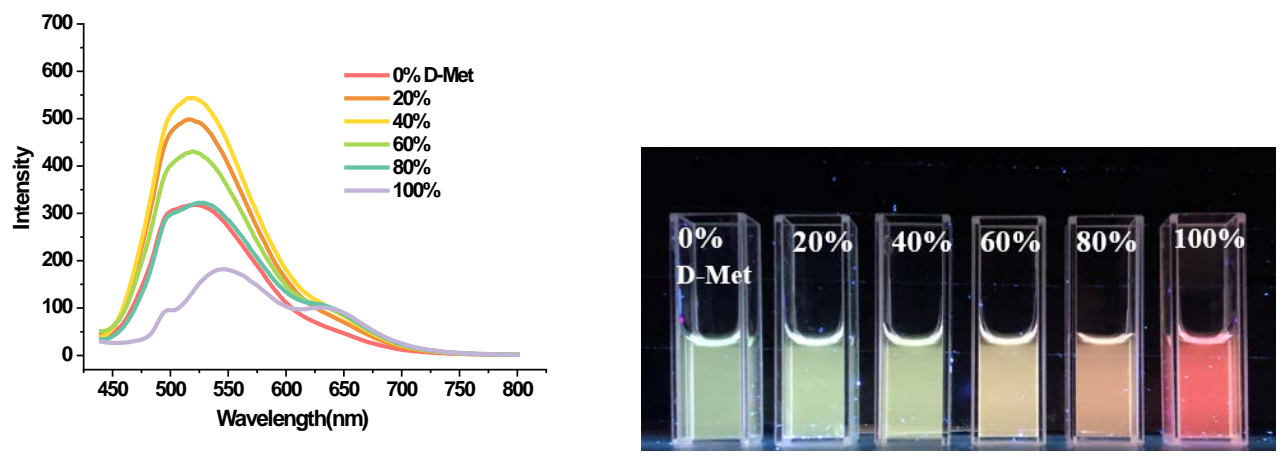


\section{Fluorescence spectra of $(R)-5$ with amino acids}

Figure S9. Fluorescence spectra of $(R)-5+\mathrm{Zn}^{2+}$ (2 equiv) $(20 \mu \mathrm{M})$ with various equiv of DArg or L-Arg in $50 \mathrm{mM}$ HEPES $(\mathrm{pH}=7.4) / 1 \%$ DMSO. Fluorescence intensity at $655 \mathrm{~nm}$ versus the equiv of arginine. The fluorescence spectra were recorded at $5{ }^{\circ} \mathrm{C}$ after mixing at room temperature for $3 \mathrm{~h}$ and then chilled in an ice bath for $30 \min (\lambda \mathrm{exc}=420 \mathrm{~nm}$, slits:5/5 $\mathrm{nm})$.
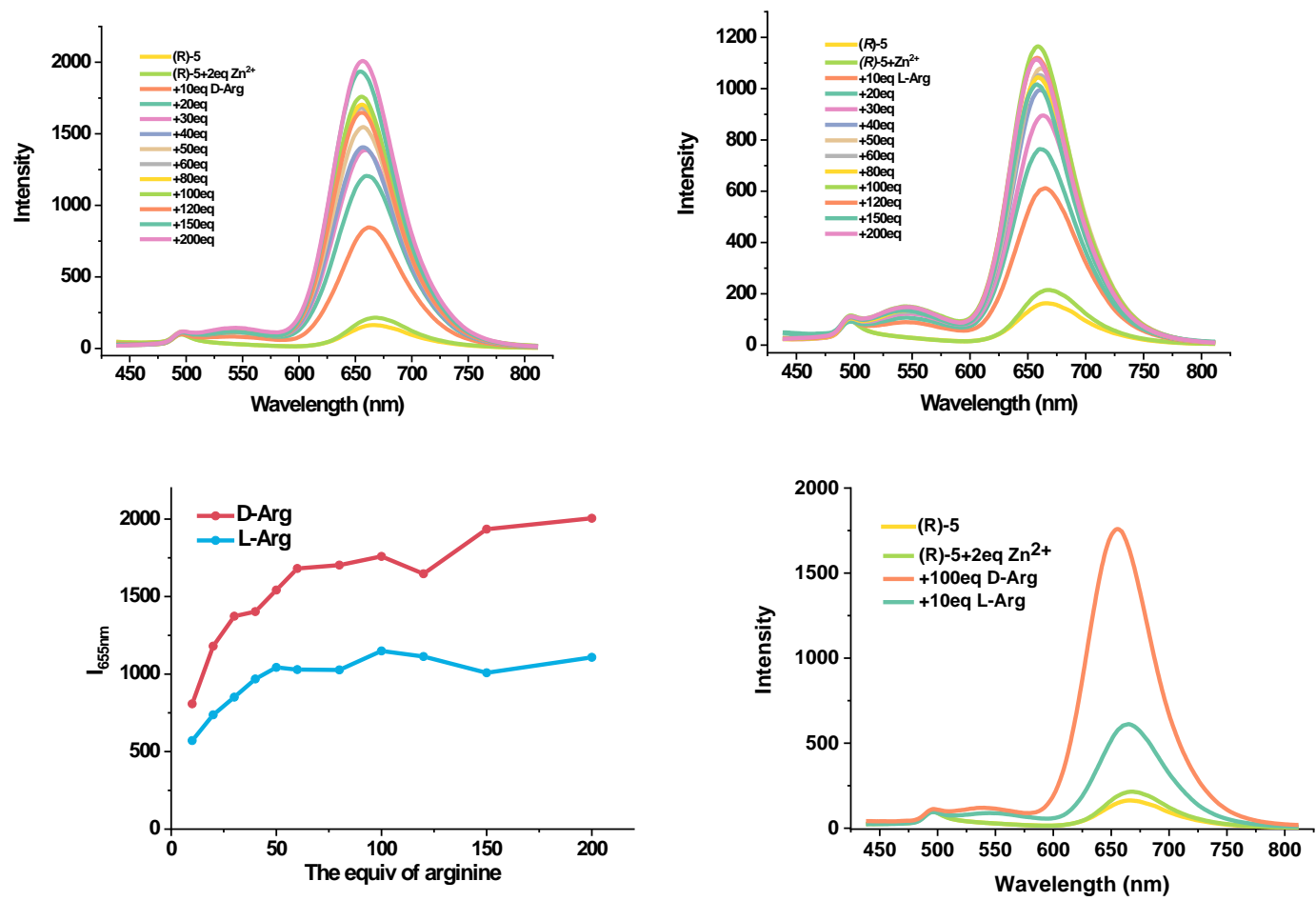
Figure S10. Fluorescence spectra of $(R)-5+\mathrm{Zn}^{2+}$ (2 equiv) $(20 \mu \mathrm{M})$ with various equiv of DAsn or L-Asn in $50 \mathrm{mM}$ HEPES $(\mathrm{pH}=7.4) / 1 \%$ DMSO. Fluorescence intensity at $655 \mathrm{~nm}$ versus the equiv of asparagine. The fluorescence spectra were recorded at $5{ }^{\circ} \mathrm{C}$ after mixing at room temperature for $3 \mathrm{~h}$ and then chilled in an ice bath for $30 \min (\lambda$ exc $=420 \mathrm{~nm}$, slits:5/5 $\mathrm{nm})$.
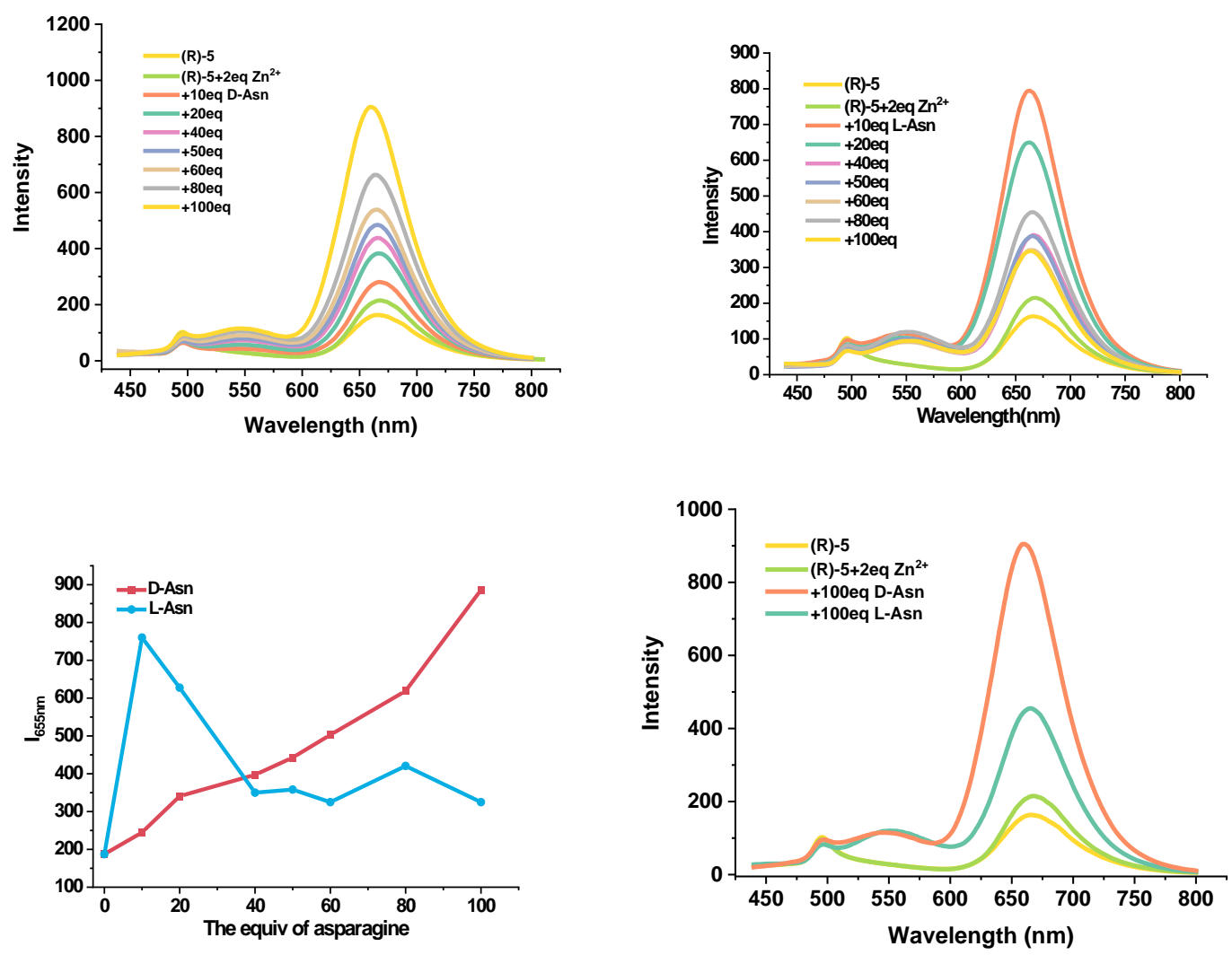

Figure S11. Fluorescence spectra of $(R)-5+\mathrm{Zn}^{2+}$ (2 equiv) $(20 \mu \mathrm{M})$ with various equiv of DGlu or L-Glu in $50 \mathrm{mM}$ HEPES $(\mathrm{pH}=7.4) / 1 \%$ DMSO. Fluorescence intensity at $655 \mathrm{~nm}$ versus the equiv of glutamic acid. The fluorescence spectra were recorded at $5{ }^{\circ} \mathrm{C}$ after mixing at room temperature for $3 \mathrm{~h}$ and then chilled in an ice bath for $30 \mathrm{~min}$ ( $\lambda$ exc $=420 \mathrm{~nm}$, slits:5/5 nm).
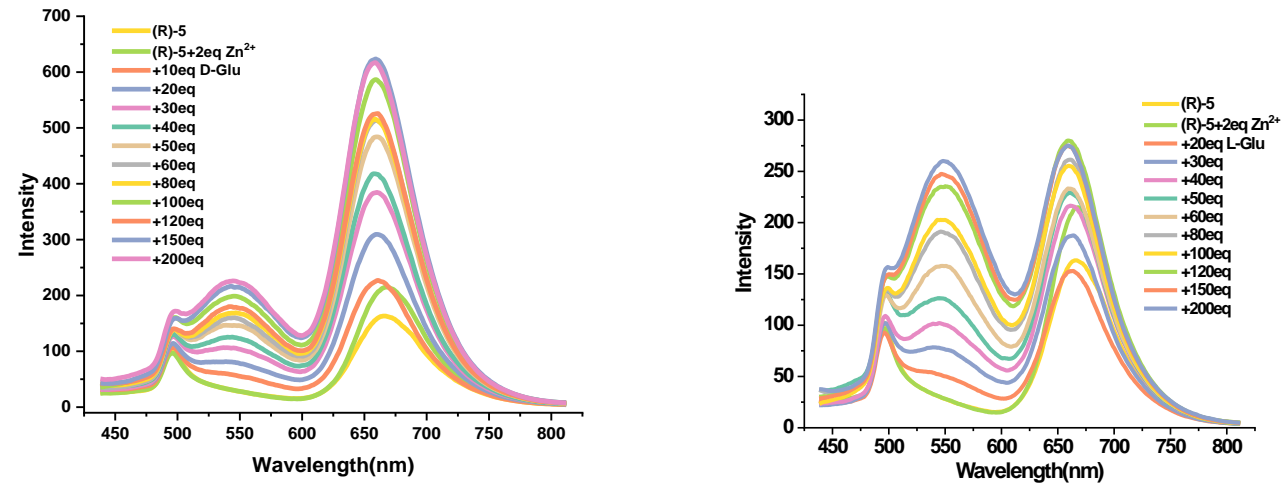

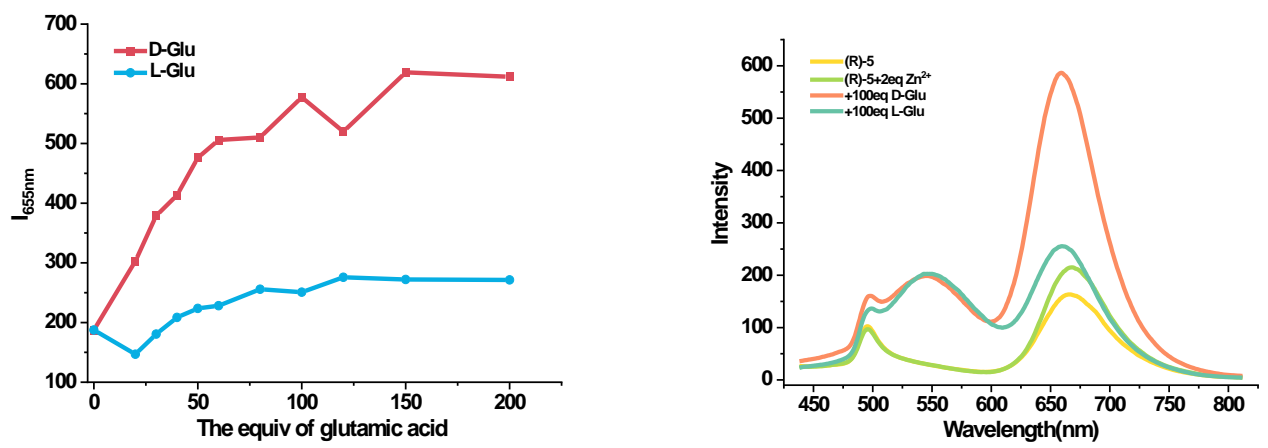

Figure S12. Fluorescence spectra of $(R)-5+\mathrm{Zn}^{2+}$ (2 equiv) $(20 \mu \mathrm{M})$ with various equiv of DHis or L-His in $50 \mathrm{mM}$ HEPES $(\mathrm{pH}=7.4) / 1 \%$ DMSO. Fluorescence intensity at $655 \mathrm{~nm}$ versus the equiv of histidine. The fluorescence spectra were recorded at $5{ }^{\circ} \mathrm{C}$ after mixing at room temperature for $3 \mathrm{~h}$ and then chilled in an ice bath for $30 \mathrm{~min}(\lambda$ exc $=420 \mathrm{~nm}$, slits:5/5 $\mathrm{nm})$.
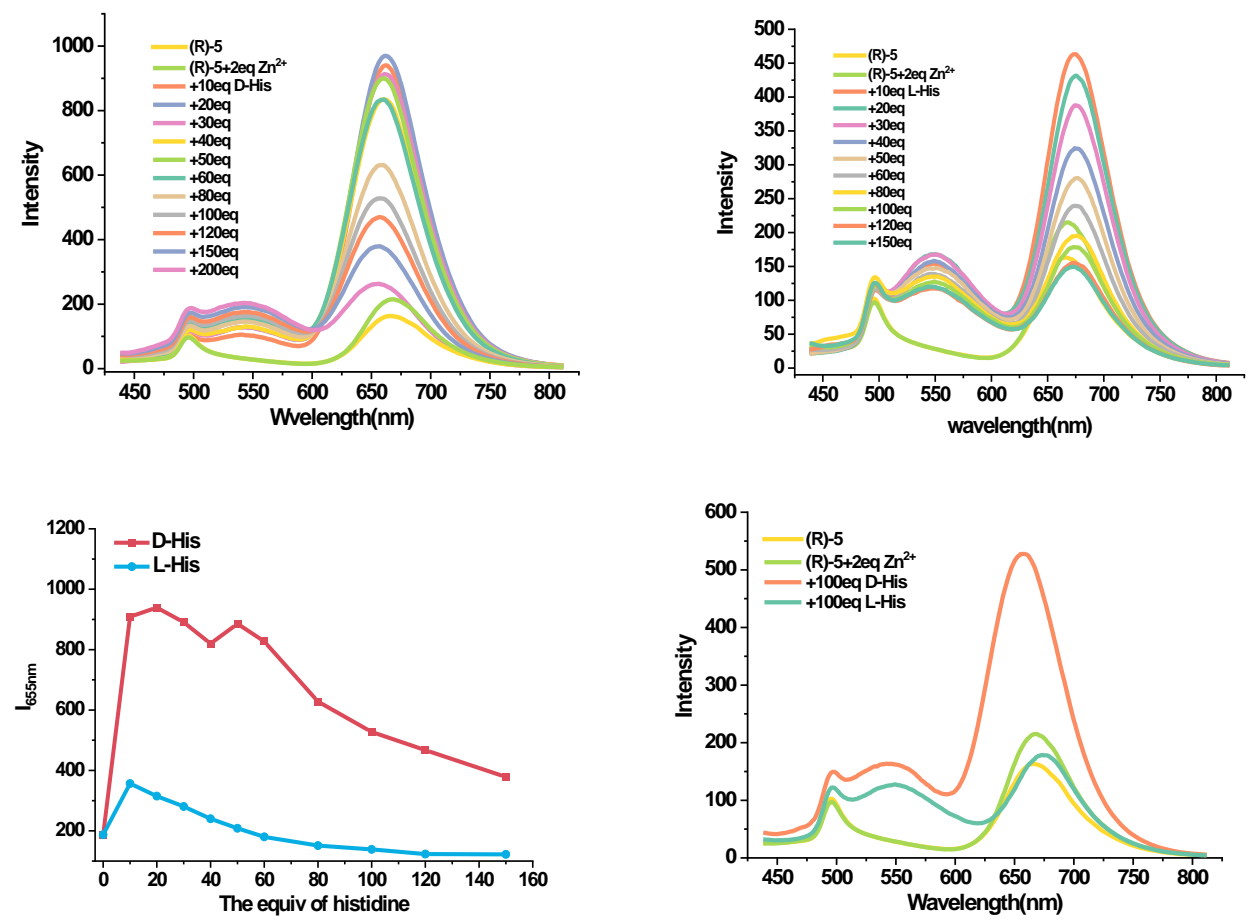
Figure S13. Fluorescence spectra of $(R)-5+\mathrm{Zn}^{2+}$ (2 equiv) $(20 \mu \mathrm{M})$ with various equiv of DLeu or L-Leu in $50 \mathrm{mM}$ HEPES $(\mathrm{pH}=7.4) / 1 \%$ DMSO. Fluorescence intensity at $655 \mathrm{~nm}$ versus the equiv of leucine. The fluorescence spectra were recorded at $5{ }^{\circ} \mathrm{C}$ after mixing at room temperature for $3 \mathrm{~h}$ and then chilled in an ice bath for $30 \mathrm{~min}(\lambda$ exc $=420 \mathrm{~nm}$, slits:5/5 $\mathrm{nm})$.
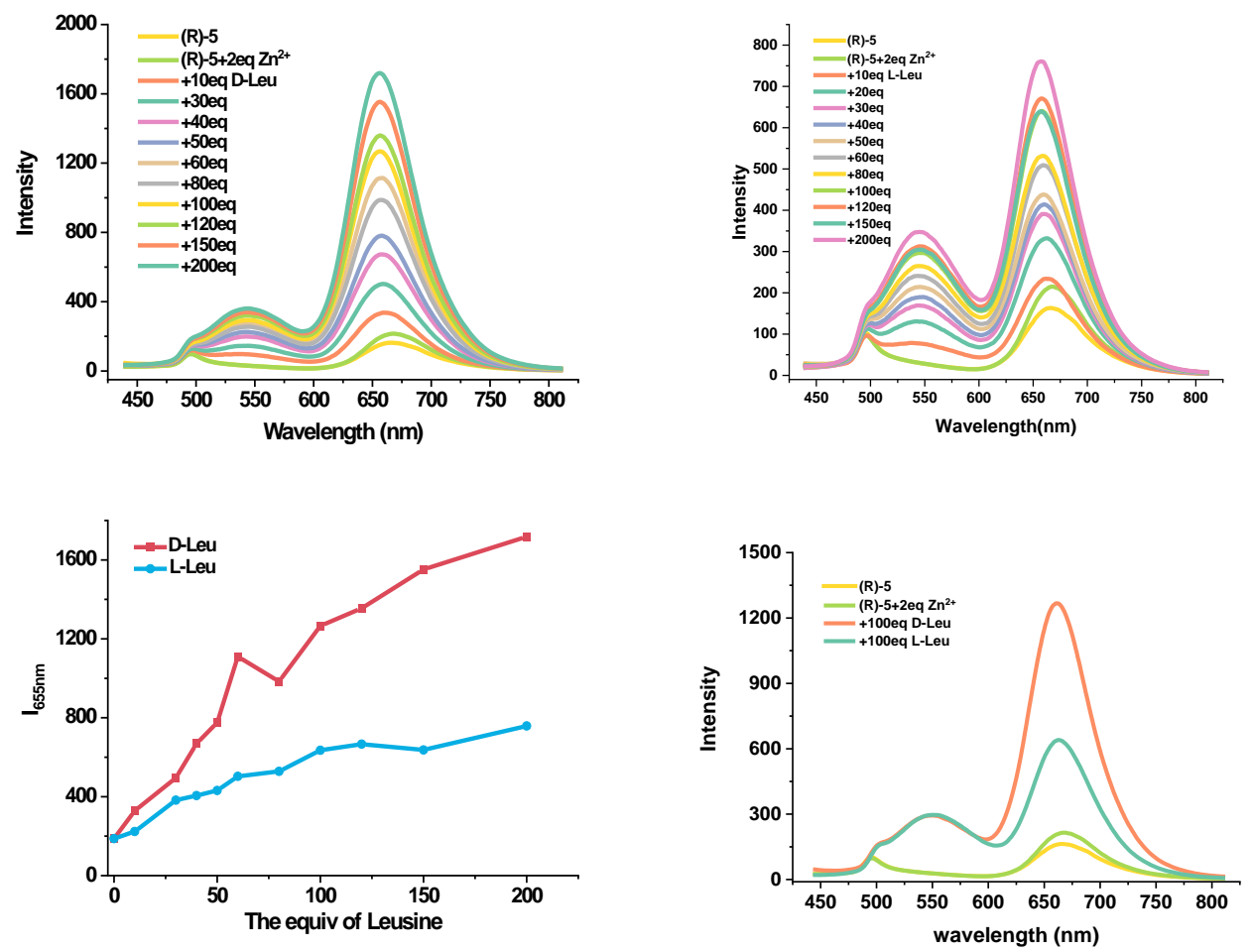

Figure S14. Fluorescence spectra of $(R)-5+\mathrm{Zn}^{2+}$ (2 equiv) $(20 \mu \mathrm{M})$ with various equiv of $\mathrm{D}-$ Lys or L-Lys in $50 \mathrm{mM}$ HEPES $(\mathrm{pH}=7.4) / 1 \%$ DMSO. Fluorescence intensity at $655 \mathrm{~nm}$ versus the equiv of lysine. The fluorescence spectra were recorded at $5{ }^{\circ} \mathrm{C}$ after mixing at room temperature for $3 \mathrm{~h}$ and then chilled in an ice bath for $30 \min (\lambda \mathrm{exc}=420 \mathrm{~nm}$, slits:5/5 $\mathrm{nm})$.
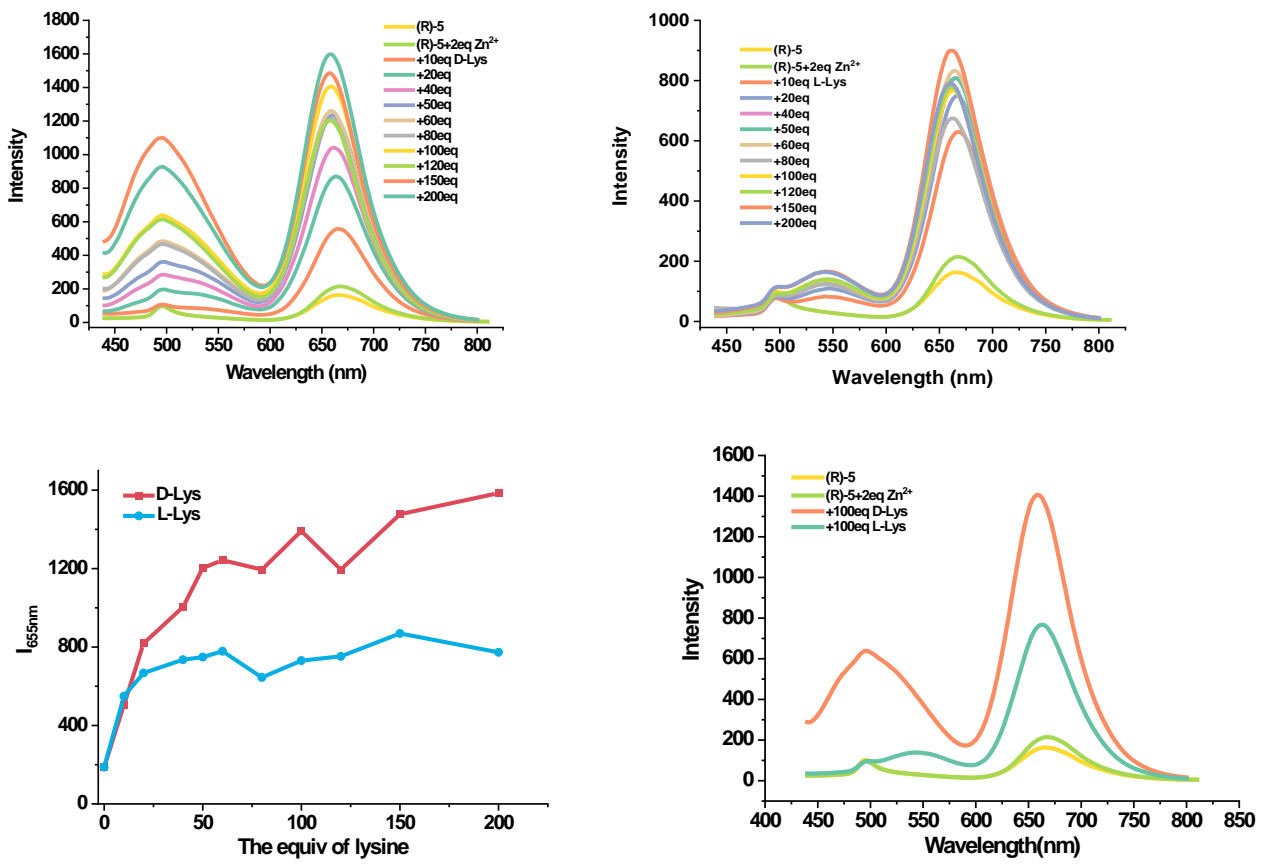
Figure S15. Fluorescence spectra of $(R)-5+\mathrm{Zn}^{2+}$ (2 equiv) $(20 \mu \mathrm{M})$ with various equiv of DPhe or L-Phe in $50 \mathrm{mM}$ HEPES $(\mathrm{pH}=7.4) / 1 \%$ DMSO. Fluorescence intensity at $655 \mathrm{~nm}$ versus the equiv of phenylalanine. The fluorescence spectra were recorded at $5{ }^{\circ} \mathrm{C}$ after mixing at room temperature for $3 \mathrm{~h}$ and then chilled in an ice bath for $30 \mathrm{~min}(\lambda \mathrm{exc}=420 \mathrm{~nm}$, slits:5/5 nm).
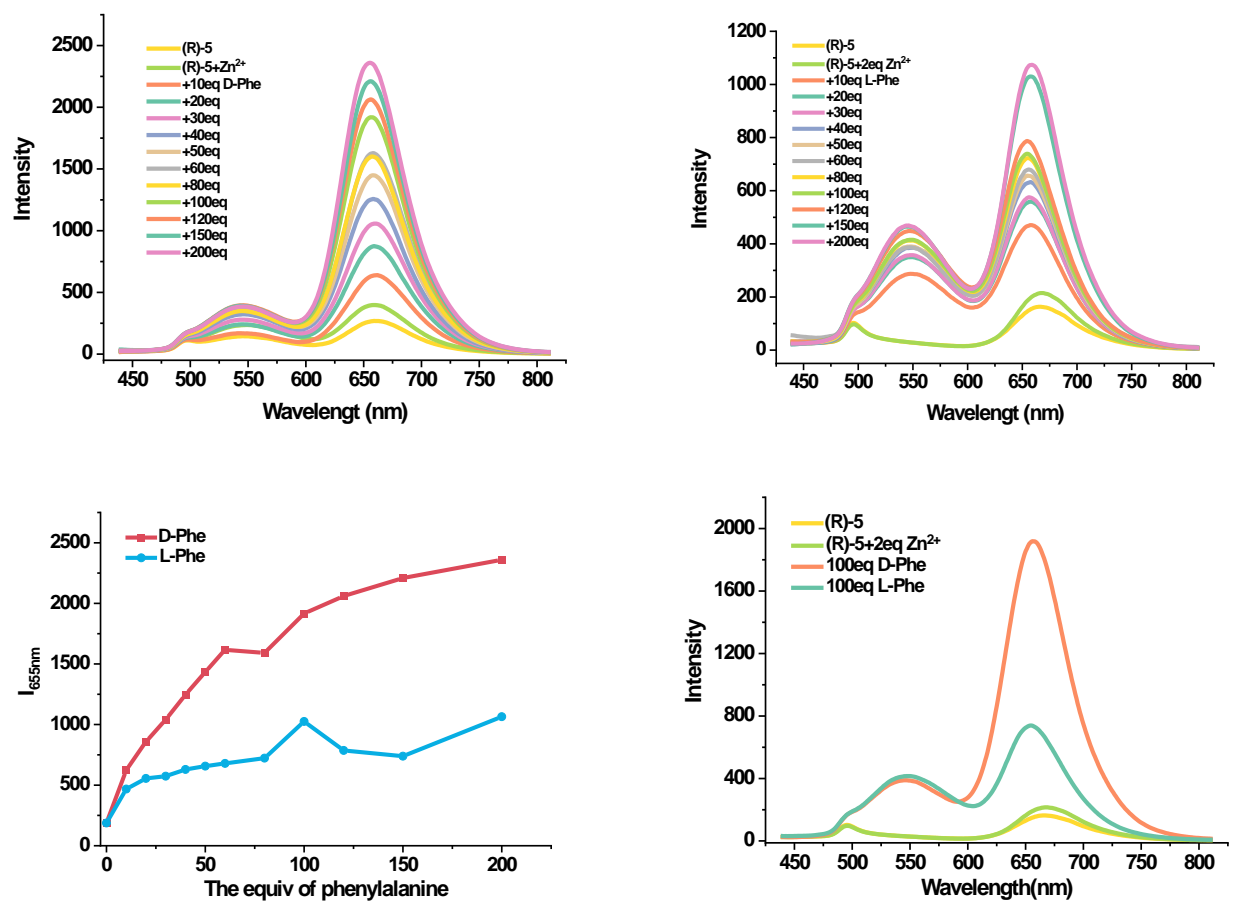

Figure S16. Fluorescence spectra of $(R)-5+\mathrm{Zn}^{2+}$ (2 equiv) $(20 \mu \mathrm{M})$ with various equiv of DTrp or L-Trp in $50 \mathrm{mM}$ HEPES $(\mathrm{pH}=7.4) / 1 \%$ DMSO. Fluorescence intensity at $655 \mathrm{~nm}$ versus the equiv of tryptophan. The fluorescence spectra were recorded at $5{ }^{\circ} \mathrm{C}$ after mixing at room temperature for $3 \mathrm{~h}$ and then chilled in an ice bath for $30 \min (\lambda$ exc $=420 \mathrm{~nm}$, slits:5/5 $\mathrm{nm})$.
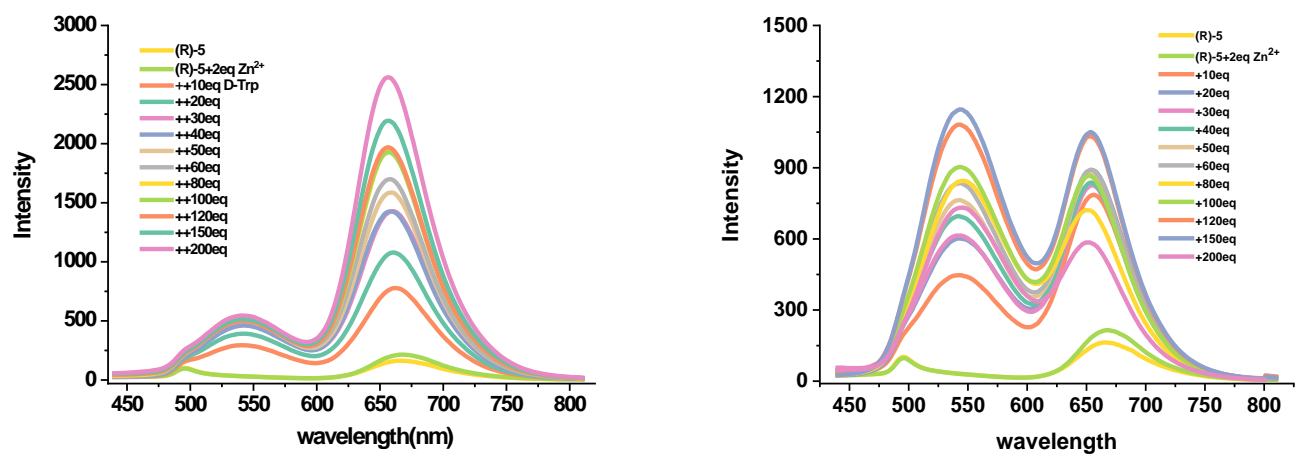

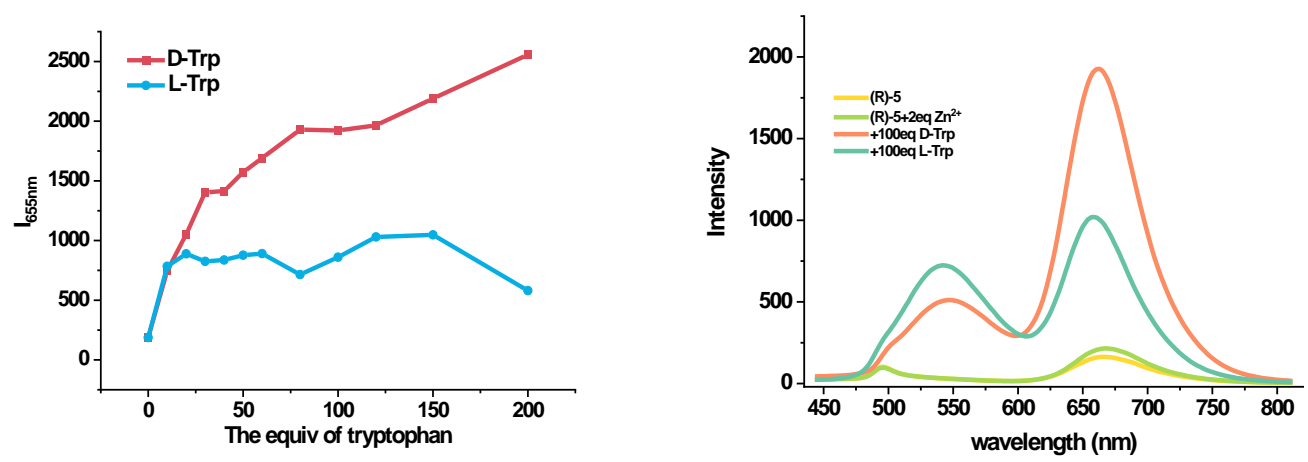

Figure S17. Fluorescence spectra of $(R)-5+\mathrm{Zn}^{2+}$ (2 equiv) $(20 \mu \mathrm{M})$ with various equiv of DVal or L-Val in $50 \mathrm{mM}$ HEPES $(\mathrm{pH}=7.4) / 1 \%$ DMSO. Fluorescence intensity at $655 \mathrm{~nm}$ versus the equiv of valine. The fluorescence spectra were recorded at $5{ }^{\circ} \mathrm{C}$ after mixing at room temperature for $3 \mathrm{~h}$ and then chilled in an ice bath for $30 \min (\lambda \mathrm{exc}=420 \mathrm{~nm}$, slits:5/5 $\mathrm{nm})$.
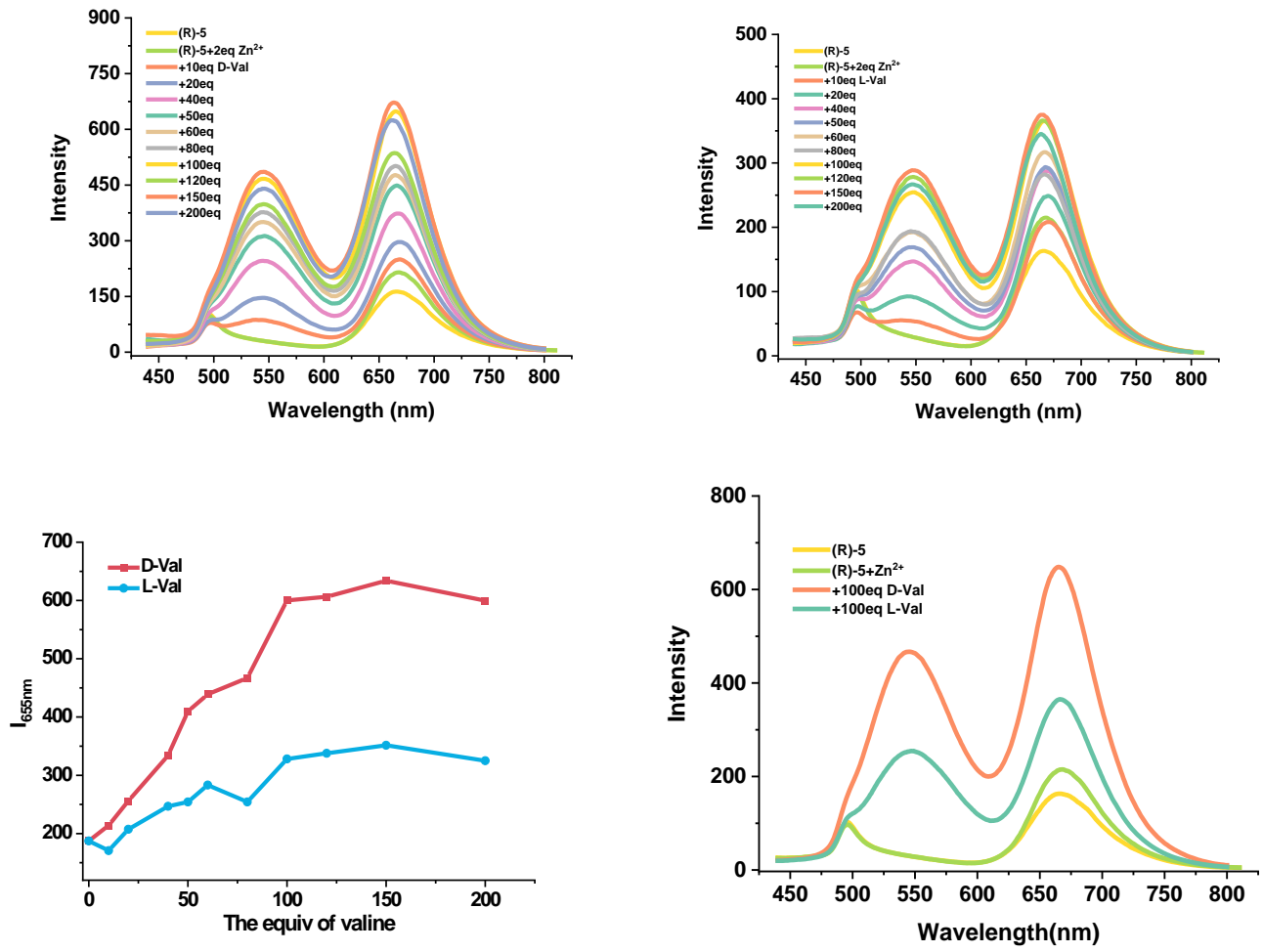


\section{Visual quantification of the enantiomeric composition of amino acids}

5.1 Visual quantification of the enantiomeric composition of histidine

Figure S18. The fluorescence spectra and visualization test of $(R)-\mathbf{5}+(S)-\mathbf{4}$ (at various ratios) $+\mathrm{Zn}^{2+}$ (2 equiv, $40 \mu \mathrm{M}$ ) with 50 equiv $D$-His or 50 equiv $L$-His in $50 \mathrm{mM}$ HEPES. The fluorescence spectra were recorded at room temperature after mixing for $3 \mathrm{~h}(\lambda \mathrm{exc}=420 \mathrm{~nm}$, slits:5/5 nm).
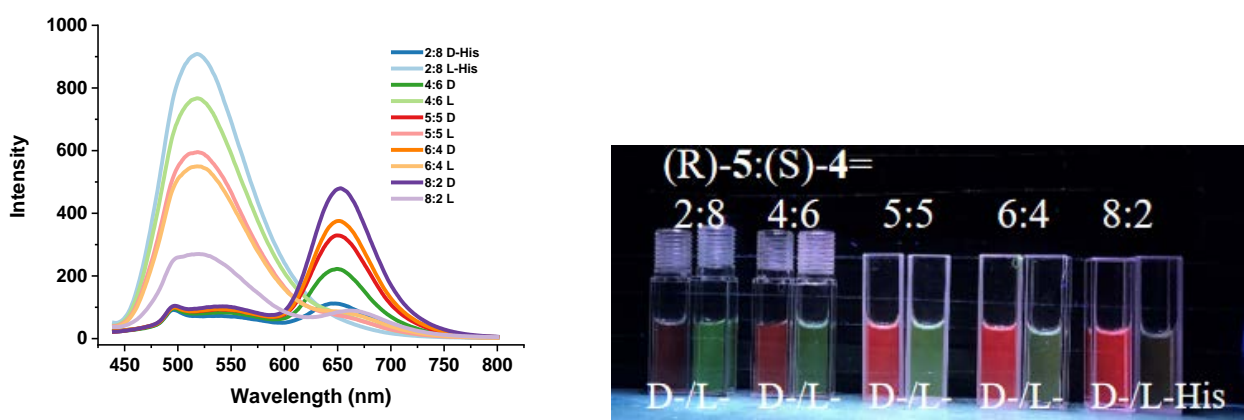

Figure S18(a). The fluorescence spectra and visualization test of $(R)-\mathbf{5}$ and $(S)-\mathbf{4}$ at various ratios $+\mathrm{Zn}^{2+}$ (2 equiv, $40 \mu \mathrm{M}$ ) with 25 equiv $D$-His +25 equiv $L$-His in $50 \mathrm{mM}$ HEPES. The fluorescence spectra were recorded at room temperature after mixing for $3 \mathrm{~h}(\lambda \mathrm{exc}=420 \mathrm{~nm}$, slits:5/5 nm).
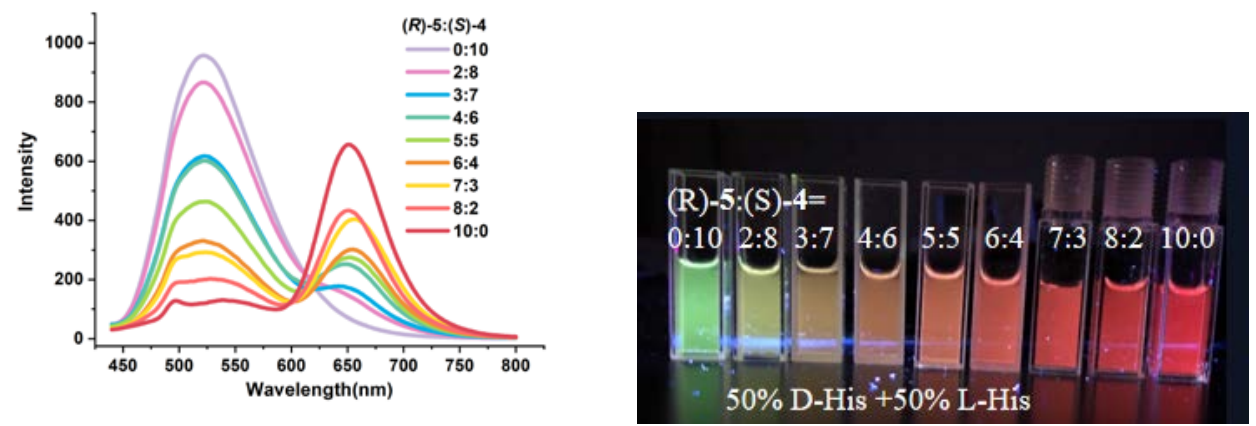

Figure S18(b). $\quad(R)-5:(S)-4=1: 4(4 \mu \mathrm{M}+16 \mu \mathrm{M})$. The fluorescence spectra and visualization test of $(R)-5(10 \mu \mathrm{M}$ in DMSO $)+(S)-4(10 \mu \mathrm{M}$ in $\mathrm{MeOH})+\mathrm{Zn}^{2+}$ (2 equiv, $\left.40 \mu \mathrm{M}\right)$ with different enantiomeric composition of His (50 equiv) in $50 \mathrm{mM}$ HEPES. The fluorescence spectra were recorded at room temperature after mixing for $3 \mathrm{~h}(\lambda$ exc $=420 \mathrm{~nm}$, slits:5/5 nm).
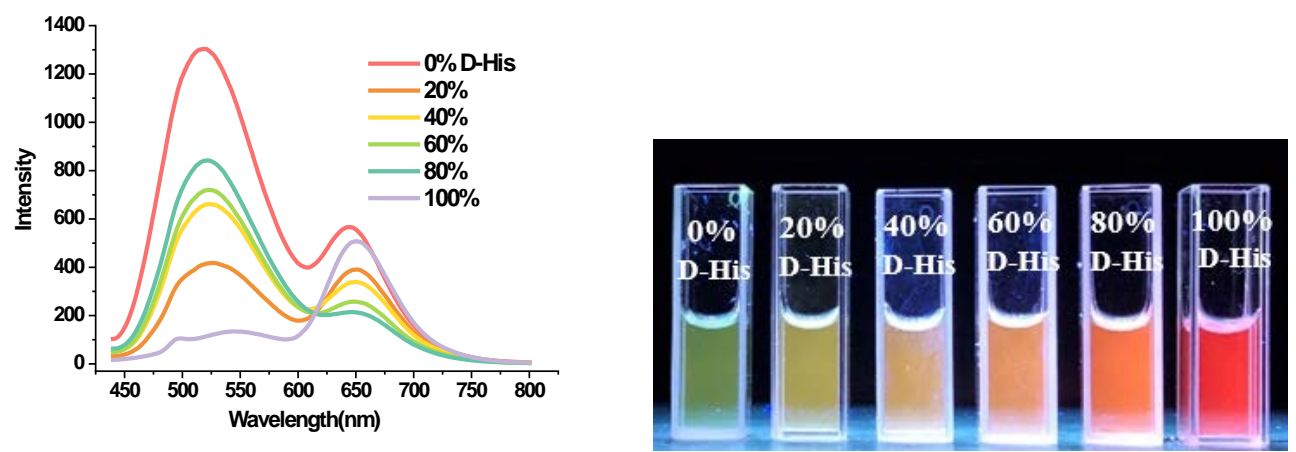
5.2 Visual quantification of the enantiomeric composition of asparagine

Figure S19. The fluorescence spectra and visualization test of $(R)-\mathbf{5}+(S)-\mathbf{4}$ (at various ratios) $+\mathrm{Zn}^{2+}$ (2 equiv, $40 \mu \mathrm{M}$ ) with 100 equiv $D$-Asn or 100 equiv $L$-Asn in $50 \mathrm{mM}$ HEPES. The fluorescence spectra were recorded at room temperature after mixing for $3 \mathrm{~h}(\lambda \mathrm{exc}=420 \mathrm{~nm}$, slits:5/5 nm).
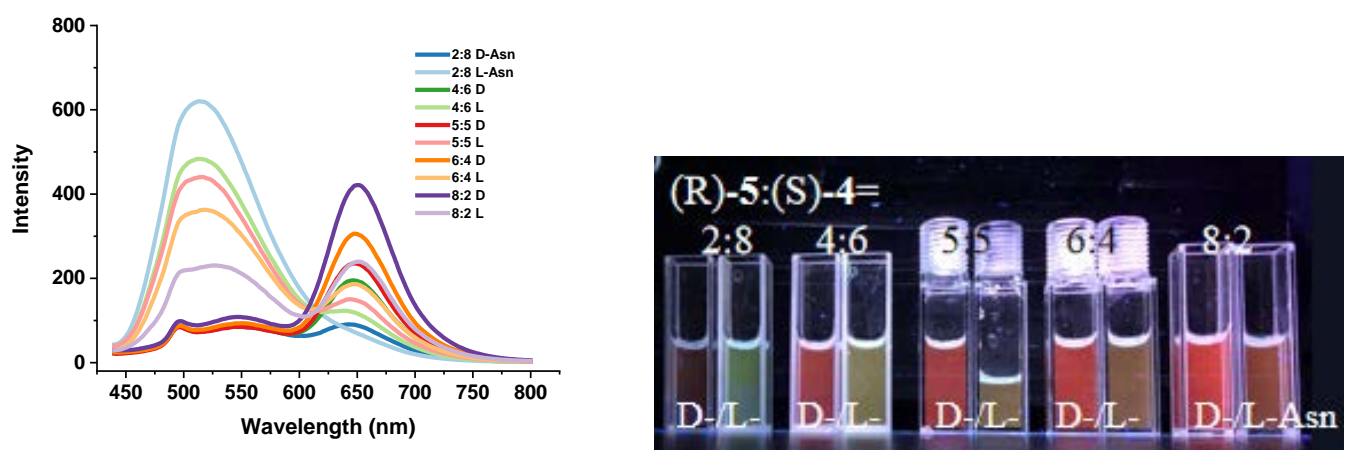

Figure S19(a). $\quad(R)-\mathbf{5}:(S)-4=1: 1 \quad(10 \mu \mathrm{M}+10 \mu \mathrm{M})$. The fluorescence spectra and visualization test of $(R)-5(10 \mu \mathrm{M}$ in DMSO $)+(S)-4(10 \mu \mathrm{M}$ in $\mathrm{MeOH})+\mathrm{Zn}^{2+}$ (2 equiv, 40 $\mu \mathrm{M})$ with different enantiomeric composition of Asn (100 equiv) in $50 \mathrm{mM}$ HEPES. The fluorescence spectra were recorded at room temperature after mixing for $3 \mathrm{~h}(\lambda \mathrm{exc}=420 \mathrm{~nm}$, slits:5/5 nm).
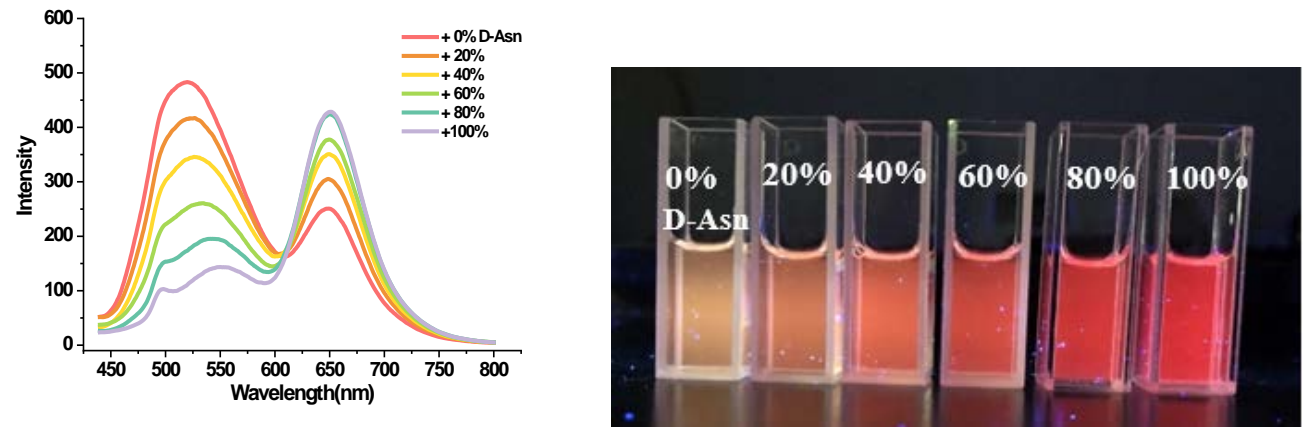

Figure S19(b). $(R)-5:(S)-4=1: 4(4 \mu \mathrm{M}+16 \mu \mathrm{M})$. The fluorescence spectra and visualization test of $(R)-5(4 \mu \mathrm{M}$ in DMSO $)+(S)-4(16 \mu \mathrm{M}$ in $\mathrm{MeOH})+\mathrm{Zn}^{2+}(2$ equiv, $40 \mu \mathrm{M})$ with different enantiomeric composition of Asn (100 equiv) in $50 \mathrm{mM}$ HEPES. The fluorescence spectra were recorded at room temperature after mixing for $3 \mathrm{~h}(\lambda$ exc $=420 \mathrm{~nm}$, slits:5/5 nm).
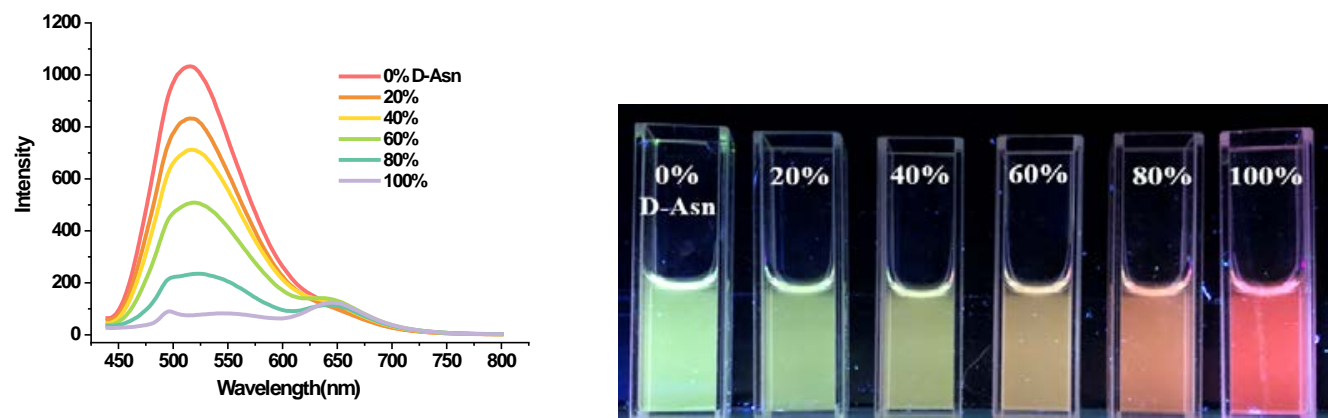
5.3 Visual quantification of the enantiomeric composition of arginine

Figure S20. The fluorescence spectra and visualization test of $(R)-\mathbf{5}+(S)-\mathbf{4}$ (at various ratios) $+\mathrm{Zn}^{2+}$ (2 equiv, $40 \mu \mathrm{M}$ ) with 100 equiv $D$-Arg or 100 equiv $L$-Arg in $50 \mathrm{mM}$ HEPES. The fluorescence spectra were recorded at room temperature after mixing for $3 \mathrm{~h}$ ( $\lambda$ exc $=420 \mathrm{~nm}$, slits:5/5 nm).
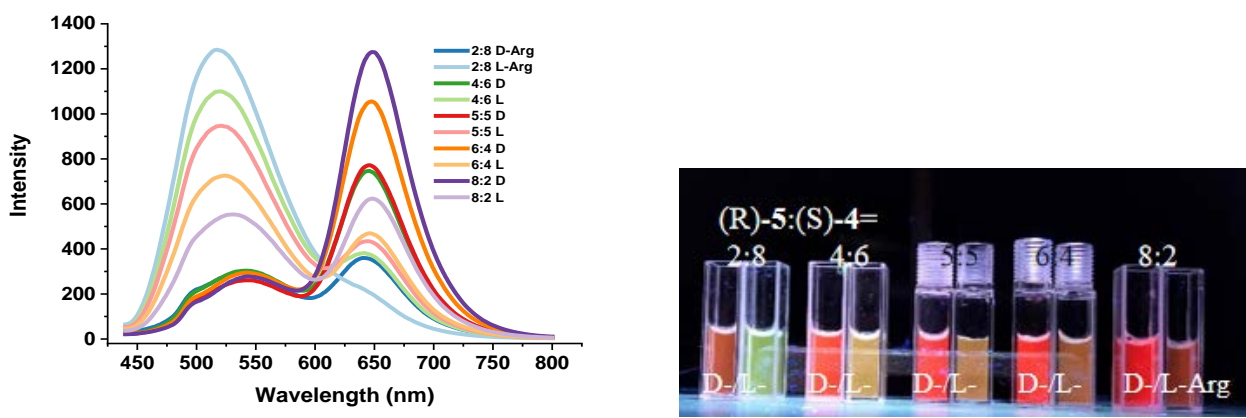

Figure S20(a). $\quad(R)-5:(S)-4=1: 1 \quad(10 \mu \mathrm{M}+10 \mu \mathrm{M})$. The fluorescence spectra and visualization analysis of $(R)-5(10 \mu \mathrm{M}$ in DMSO $)+(S)-4(10 \mu \mathrm{M}$ in $\mathrm{MeOH})+\mathrm{Zn}^{2+}$ (2 equiv, 40 $\mu \mathrm{M})$ with different enantiomeric composition of Arg (100 equiv) in $50 \mathrm{mM}$ HEPES. The fluorescence spectra were recorded at room temperature after mixing for $3 \mathrm{~h}(\lambda \mathrm{exc}=420 \mathrm{~nm}$, slits:5/5 nm).
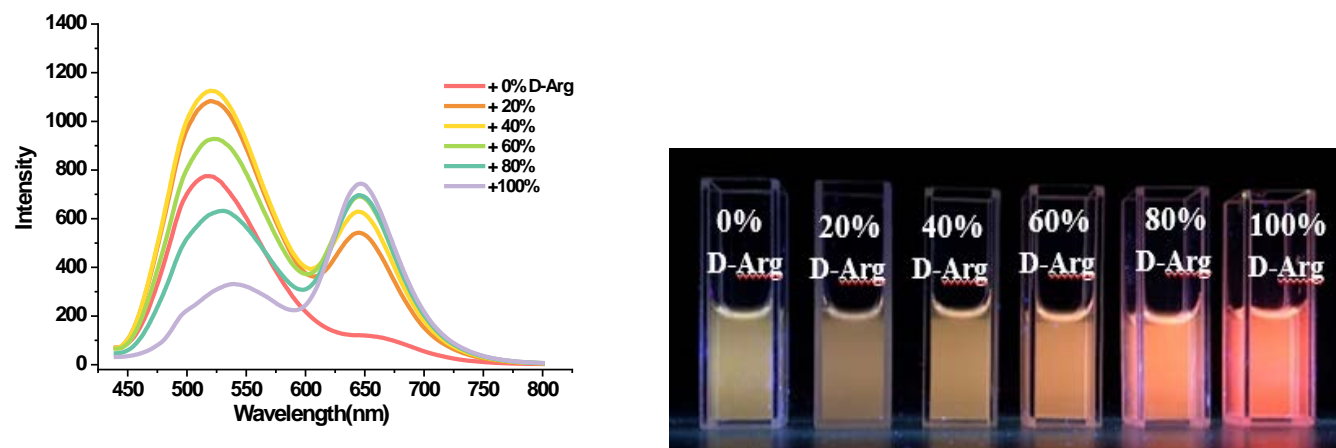

Figure S20(b). $(R)-\mathbf{5 : ( S ) - 4}=1: 4 \quad(4 \mu \mathrm{M}+16 \mu \mathrm{M})$. The fluorescence spectra and visualization analysis of $(R)-5(4 \mu \mathrm{M}$ in DMSO $)+(S)-4(16 \mu \mathrm{M}$ in $\mathrm{MeOH})+\mathrm{Zn}^{2+}$ (2 equiv, 40 $\mu \mathrm{M})$ with different enantiomeric composition of Arg (100 equiv) in $50 \mathrm{mM}$ HEPES. The fluorescence spectra were recorded at room temperature after mixing for $3 \mathrm{~h}$ ( $\lambda$ exc $=420 \mathrm{~nm}$, slits:5/5 nm).
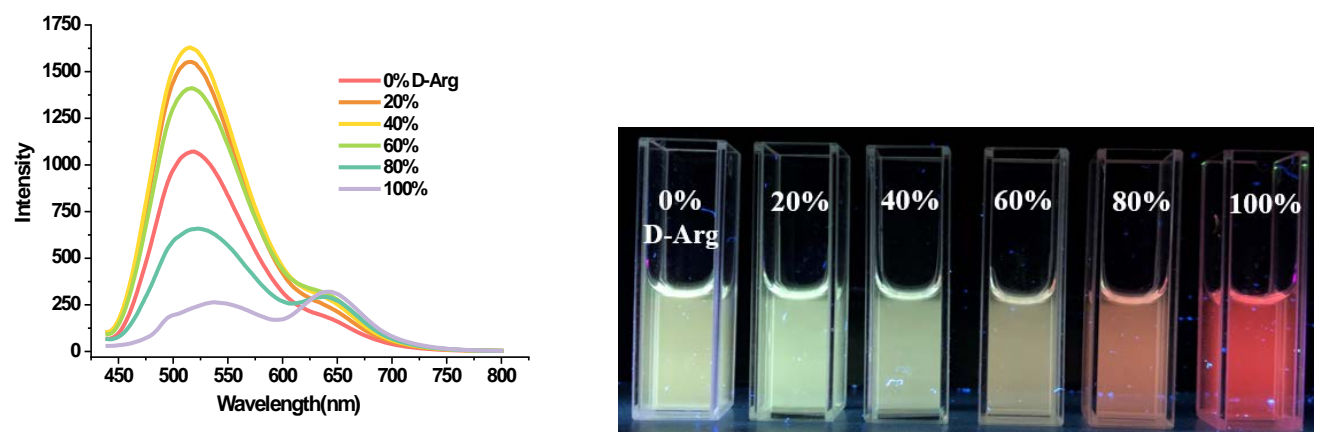
5.4 Visual quantification of the enantiomeric composition of glutamine

Figure S21. The fluorescence spectra and visualization test of $(R)-\mathbf{5}+(S)-\mathbf{4}$ (at various ratios) $+\mathrm{Zn}^{2+}$ (2 equiv, $40 \mu \mathrm{M}$ ) with 100 equiv $D$-Gln or 100 equiv $L$-Gln in $50 \mathrm{mM}$ HEPES. The fluorescence spectra were recorded at room temperature after mixing for $3 \mathrm{~h}$ ( $\lambda$ exc $=420 \mathrm{~nm}$, slits:5/5 nm).
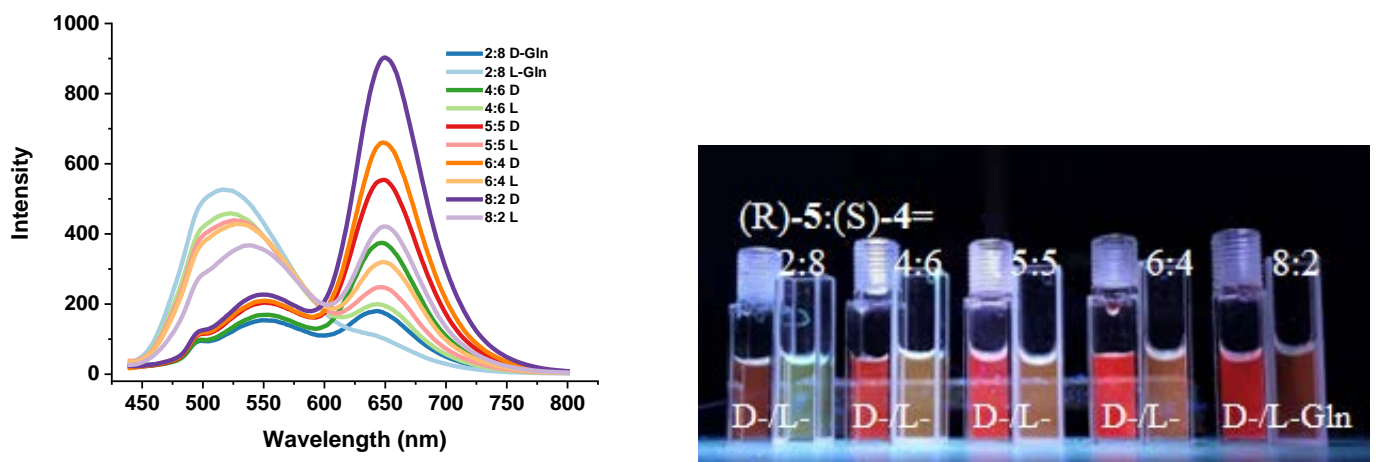

Figure S21(a). $(R)-5:(S)-4=1: 1(10 \mu \mathrm{M}+10 \mu \mathrm{M})$. The fluorescence spectra and visualization analysis of $(R)-5(10 \mu \mathrm{M}$ in DMSO $)+(S)-4(10 \mu \mathrm{M}$ in $\mathrm{MeOH})+\mathrm{Zn}^{2+}(2$ equiv, $40 \mu \mathrm{M})$ with different enantiomeric composition of Gln (100 equiv) in $50 \mathrm{mM}$ HEPES. The fluorescence spectra were recorded at room temperature after mixing for $3 \mathrm{~h}(\lambda$ exc $=420 \mathrm{~nm}$, slits:5/5 nm).
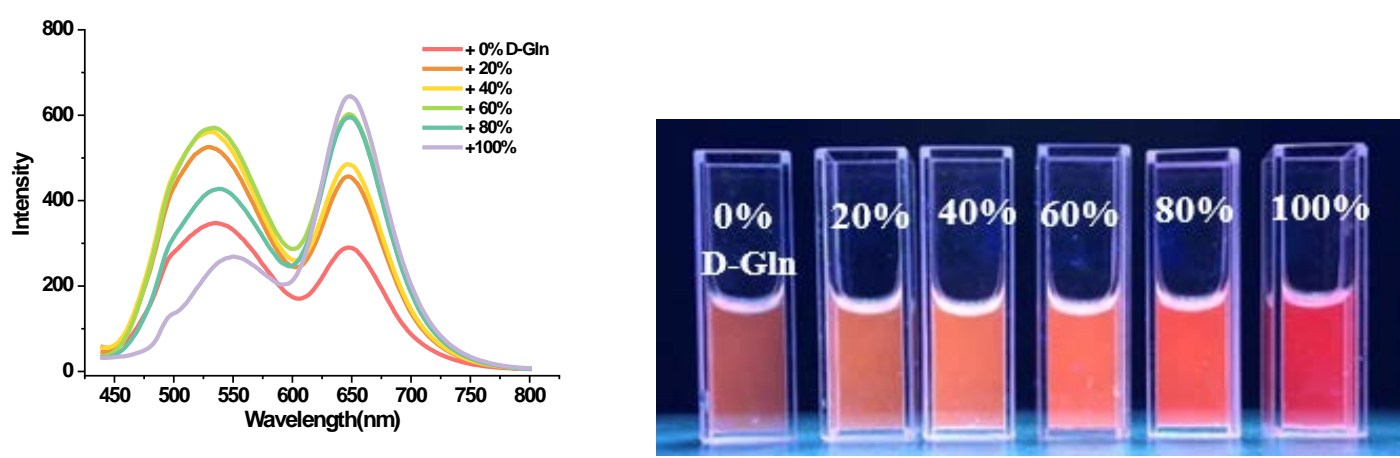

Figure S21(b). $(R)-\mathbf{5}:(S)-\mathbf{4}=1: 4(4 \mu \mathrm{M}+16 \mu \mathrm{M})$. The fluorescence spectra and visualization analysis of $(R)-5(4 \mu \mathrm{M}$ in DMSO $)+(S)-4(16 \mu \mathrm{M}$ in $\mathrm{MeOH})+\mathrm{Zn}^{2+}(2$ equiv, $40 \mu \mathrm{M})$ with different enantiomeric composition of Gln (100 equiv) in 50 mM HEPES. The fluorescence spectra were recorded at room temperature after mixing for $3 \mathrm{~h}(\lambda$ exc $=420 \mathrm{~nm}$, slits:5/5 nm).
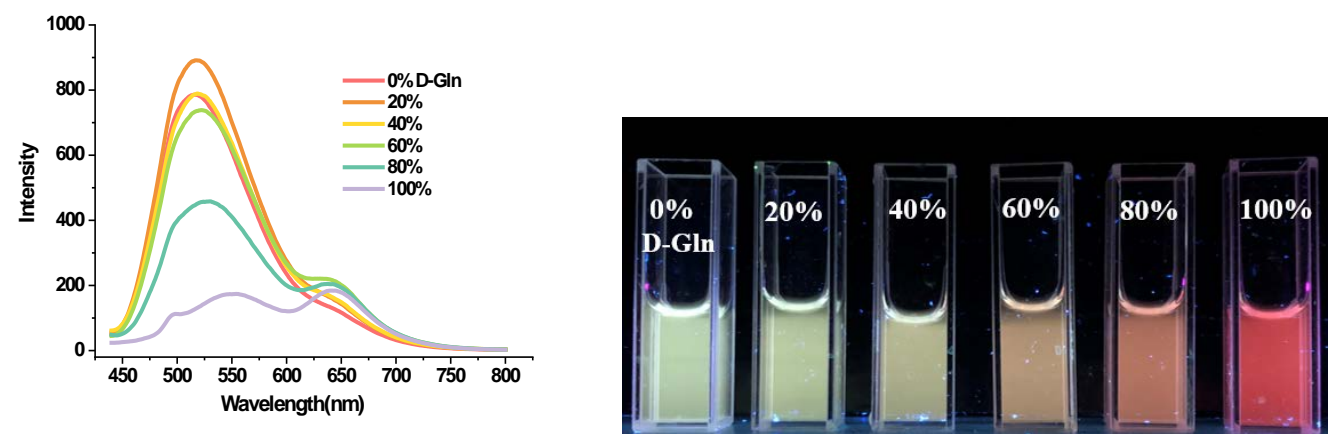
5.5 Visual quantification of the enantiomeric composition of lysine

Figure S22. The fluorescence spectra and visualization test of $(R)-\mathbf{5}+(S)-\mathbf{4}$ (at various ratios) $+\mathrm{Zn}^{2+}$ (2 equiv, $40 \mu \mathrm{M}$ ) with 100 equiv $D$-Lys or 100 equiv $L$-Lys in $50 \mathrm{mM}$ HEPES. The fluorescence spectra were recorded at room temperature after mixing for $3 \mathrm{~h}$ ( $\lambda$ exc $=420 \mathrm{~nm}$, slits:5/5 nm).
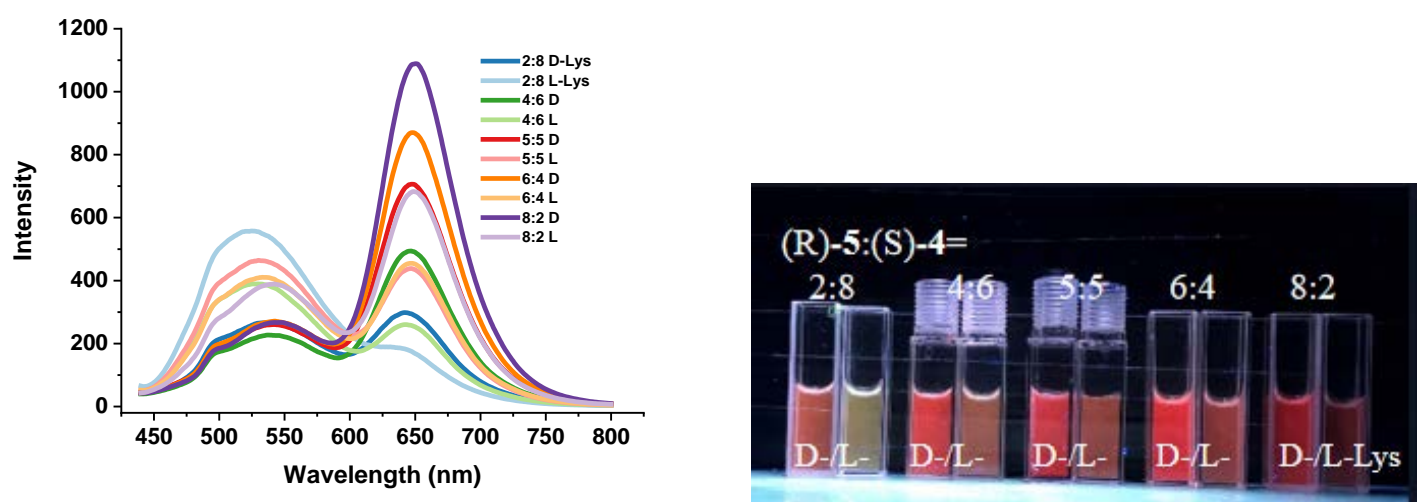

Figure S22(a). The fluorescence spectra and visualization test of $(R)-\mathbf{5}$ and (S)-4 at various ratios $+\mathrm{Zn}^{2+}$ (2 equiv, $40 \mu \mathrm{M}$ ) with 50 equiv $D$-Lys +50 equiv $L$-Lys in $50 \mathrm{mM}$ HEPES. The fluorescence spectra were recorded at room temperature after mixing for $3 \mathrm{~h}$ ( $\lambda$ exc $=420 \mathrm{~nm}$, slits:5/5 nm).
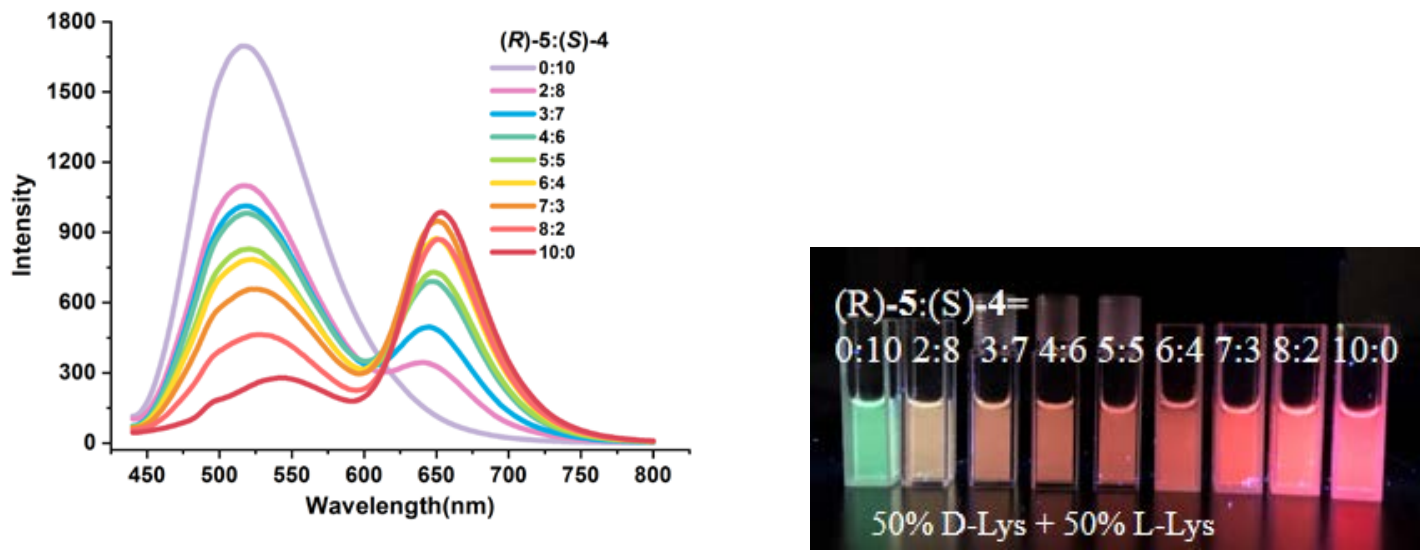
Figure S22(b). $\quad(R)-5:(S)-4=1: 1 \quad(10 \mu \mathrm{M}+10 \mu \mathrm{M})$. The fluorescence spectra and visualization analysis of $(R)-5\left(10 \mu \mathrm{M}\right.$ in DMSO) $+(S)-4(10 \mu \mathrm{M}$ in $\mathrm{MeOH})+\mathrm{Zn}^{2+}$ (2 equiv, $40 \mu \mathrm{M}$ ) with different enantiomeric composition of Lys (100 equiv) in $50 \mathrm{mM}$ HEPES. The fluorescence spectra were recorded at room temperature after mixing for $3 \mathrm{~h}(\lambda \mathrm{exc}=420 \mathrm{~nm}$, slits:5/5 nm).
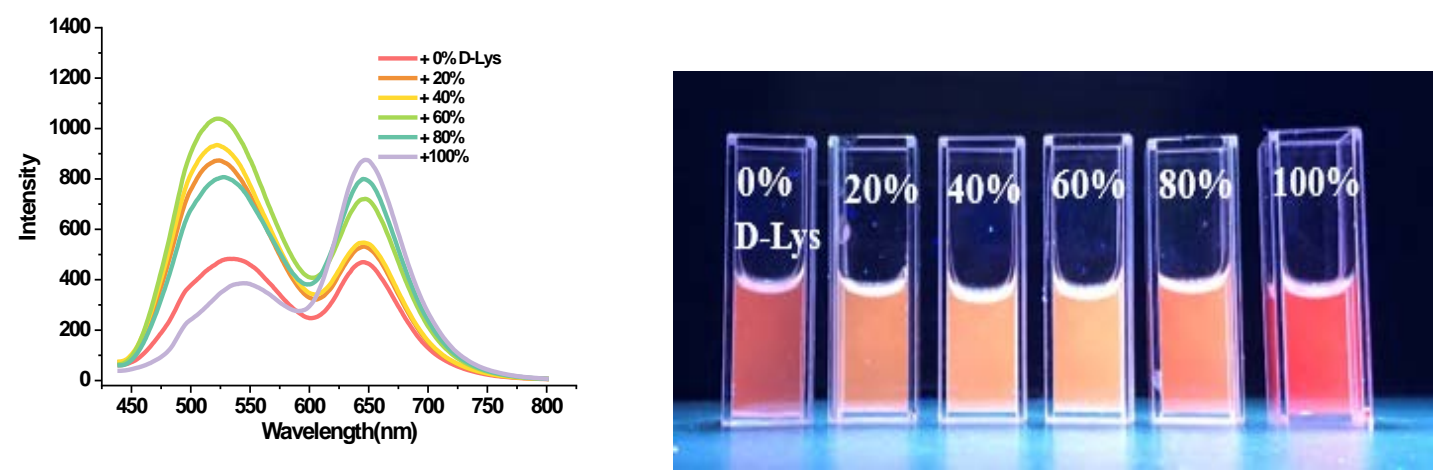

Figure S22(c). $\quad(R)-5:(S)-4=1: 4 \quad(4 \mu \mathrm{M}+16 \mu \mathrm{M})$. The fluorescence spectra and visualization analysis of $(R)-5\left(4 \mu \mathrm{M}\right.$ in DMSO) $+(S)-4(16 \mu \mathrm{M}$ in $\mathrm{MeOH})+\mathrm{Zn}^{2+}$ (2 equiv, 40 $\mu \mathrm{M}$ ) with different enantiomeric composition of Lys (100 equiv) in $50 \mathrm{mM}$ HEPES. The fluorescence spectra were recorded at room temperature after mixing for $3 \mathrm{~h}(\lambda \mathrm{exc}=420 \mathrm{~nm}$, slits:5/5 nm).
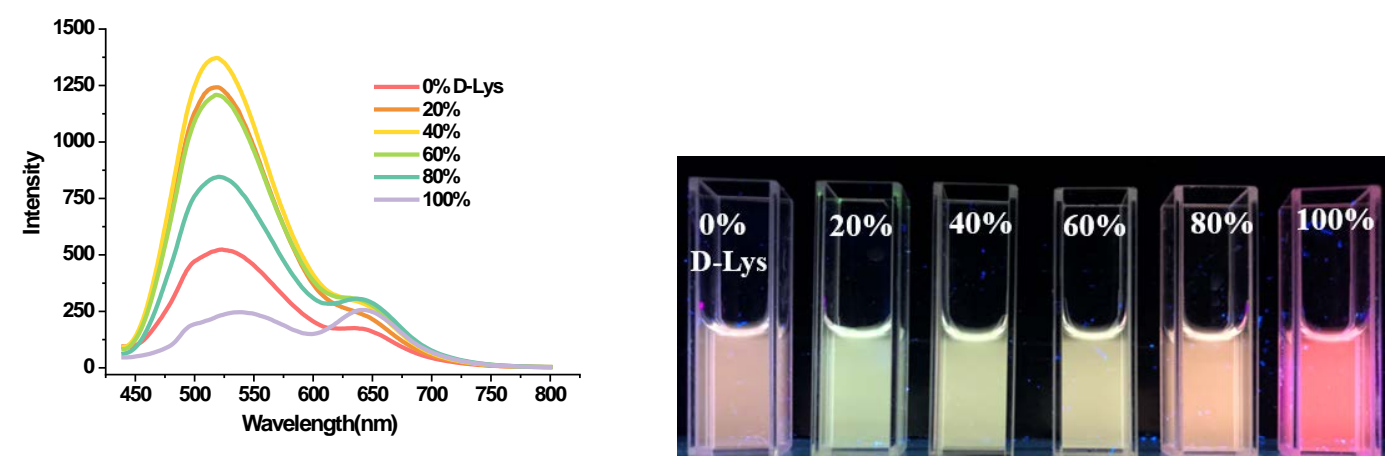

Figure S22(d). $\quad(R)-\mathbf{5}:(S)-\mathbf{4}=1: 5.7 \quad(3 \mu \mathrm{M}+17 \mu \mathrm{M})$. The fluorescence spectra and visualization analysis of $(R)-5\left(3 \mu \mathrm{M}\right.$ in DMSO) $+(S)-4(17 \mu \mathrm{M}$ in $\mathrm{MeOH})+\mathrm{Zn}^{2+}$ (2 equiv, 40 $\mu \mathrm{M}$ ) with different enantiomeric composition of Lys (100 equiv) in $50 \mathrm{mM}$ HEPES. The fluorescence spectra were recorded at room temperature after mixing for $3 \mathrm{~h}$ ( $\lambda$ exc $=420 \mathrm{~nm}$, slits:5/5 nm).
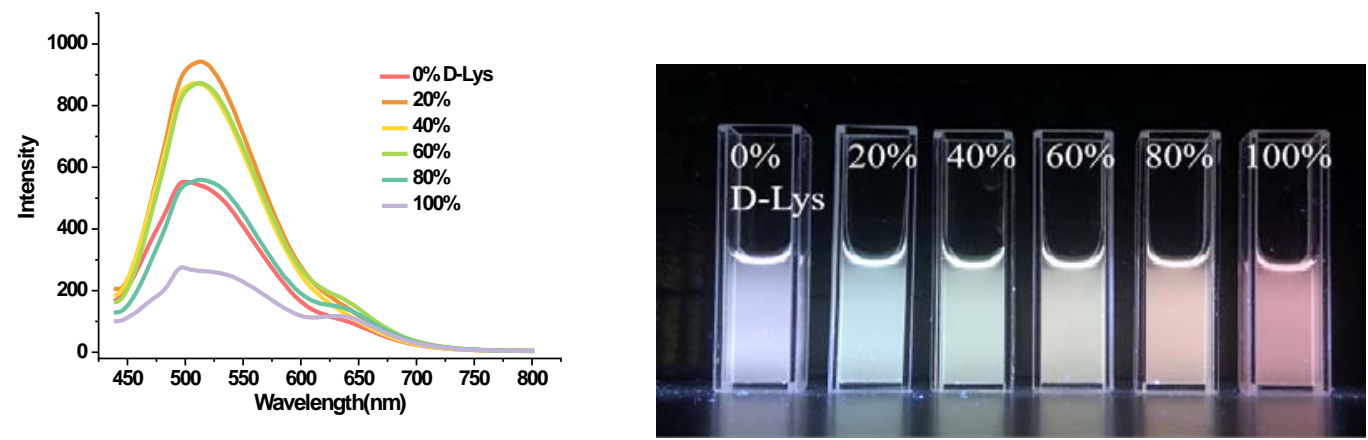
Figure S22(e). $\quad(R)-5:(S)-4=1: 9 \quad(2 \mu \mathrm{M}+18 \mu \mathrm{M})$. The fluorescence spectra and visualization analysis of $(R)-5\left(2 \mu \mathrm{M}\right.$ in DMSO) $+(S)-4(18 \mu \mathrm{M}$ in $\mathrm{MeOH})+\mathrm{Zn}^{2+}$ (2 equiv, 40 $\mu \mathrm{M})$ with different enantiomeric composition of Lys (100 equiv) in $50 \mathrm{mM}$ HEPES. The fluorescence spectra were recorded at room temperature after mixing for $3 \mathrm{~h}(\lambda \mathrm{exc}=420 \mathrm{~nm}$, slits:5/5 nm).
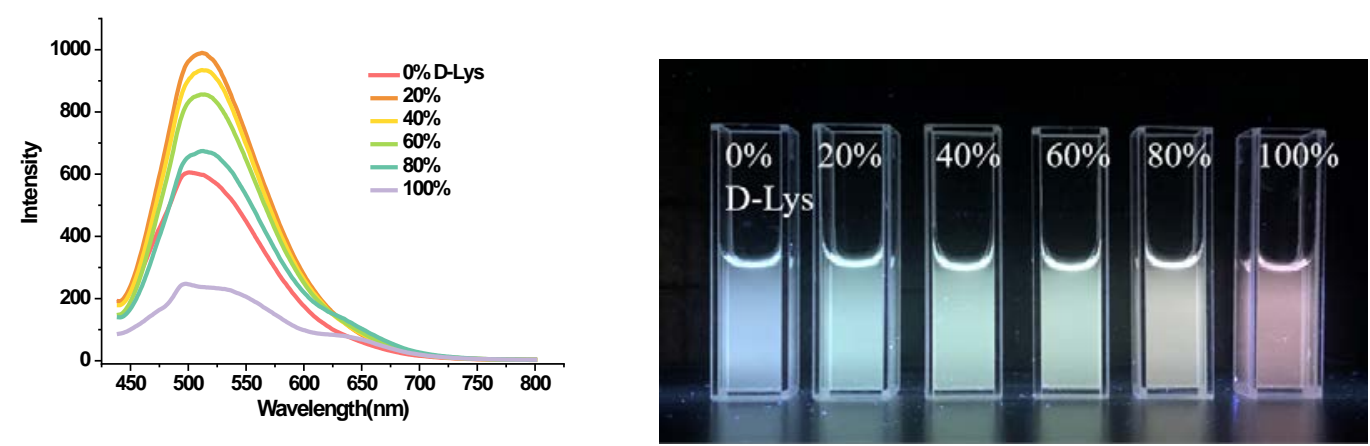

5.6 Visual quantification of the enantiomeric composition of phenylalanine

Figure S23. The fluorescence spectra and visualization test of $(R)-\mathbf{5}+(S)-\mathbf{4}$ (at various ratios)

$+\mathrm{Zn}^{2+}$ (2 equiv, $40 \mu \mathrm{M}$ ) with 100 equiv $D$-Phe or 100 equiv $L$-Phe in $50 \mathrm{mM}$ HEPES. The fluorescence spectra were recorded at room temperature after mixing for $3 \mathrm{~h}(\lambda \mathrm{exc}=420 \mathrm{~nm}$, slits:5/5 nm).
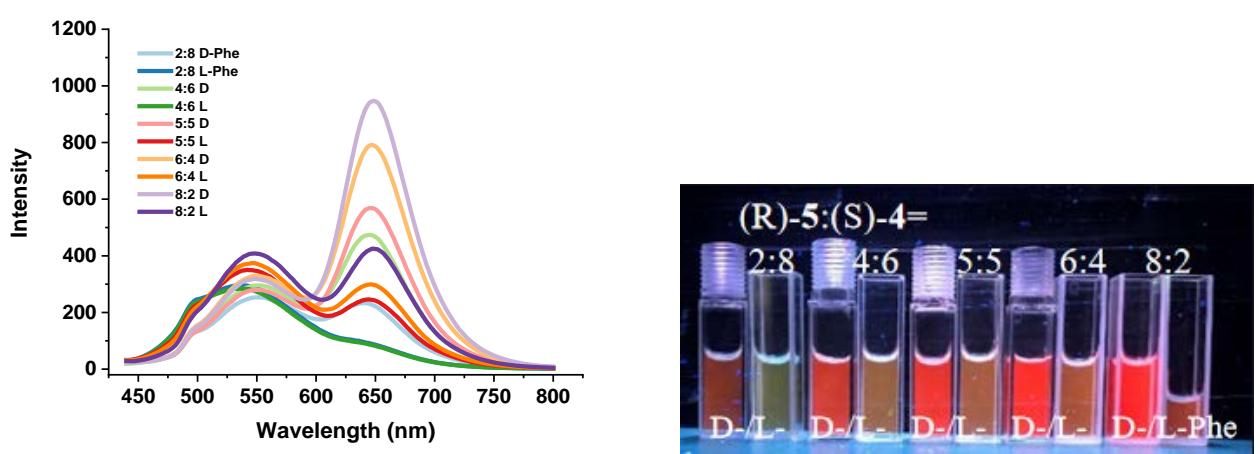

Figure S23(a). $\quad(R)-5:(S)-4=1: 1 \quad(10 \mu \mathrm{M}+10 \mu \mathrm{M})$. The fluorescence spectra and visualization analysis of $(R)-5\left(10 \mu \mathrm{M}\right.$ in DMSO) $+(S)-4(10 \mu \mathrm{M}$ in $\mathrm{MeOH})+\mathrm{Zn}^{2+}$ (2 equiv, $40 \mu \mathrm{M})$ with different enantiomeric composition of Phe (100 equiv) in $50 \mathrm{mM}$ HEPES. The fluorescence spectra were recorded at room temperature after mixing for $3 \mathrm{~h}(\lambda \mathrm{exc}=420 \mathrm{~nm}$, slits:5/5 nm).
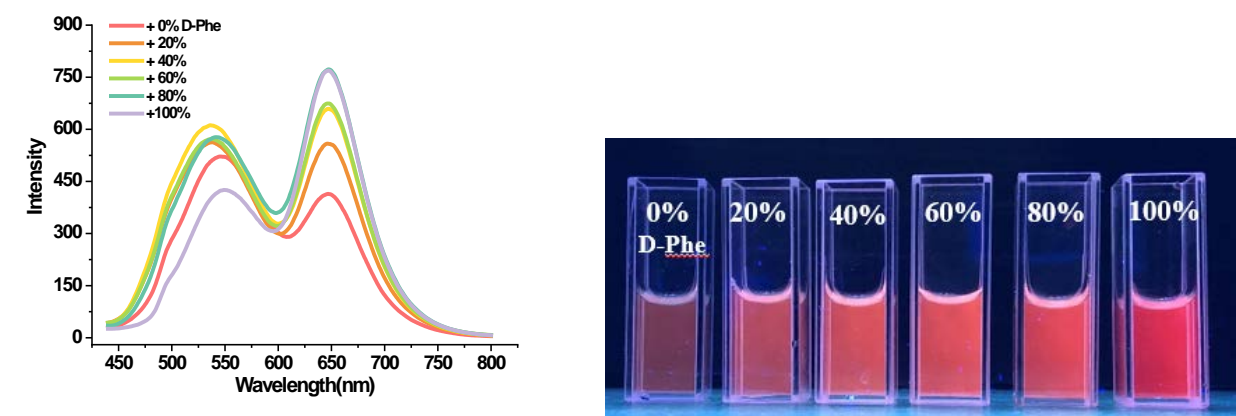
Figure S23(b). $\quad(R)-\mathbf{5 : ( S ) - 4}=1: 4 \quad(4 \mu \mathrm{M}+16 \mu \mathrm{M})$. The fluorescence spectra and visualization analysis of $(R)-5\left(4 \mu \mathrm{M}\right.$ in DMSO) $+(S)-4(16 \mu \mathrm{M}$ in $\mathrm{MeOH})+\mathrm{Zn}^{2+}$ (2 equiv, 40 $\mu \mathrm{M})$ with different enantiomeric composition of Phe (100 equiv) in $50 \mathrm{mM}$ HEPES. The fluorescence spectra were recorded at room temperature after mixing for $3 \mathrm{~h}(\lambda \operatorname{exc}=420 \mathrm{~nm}$, slits:5/5 nm).
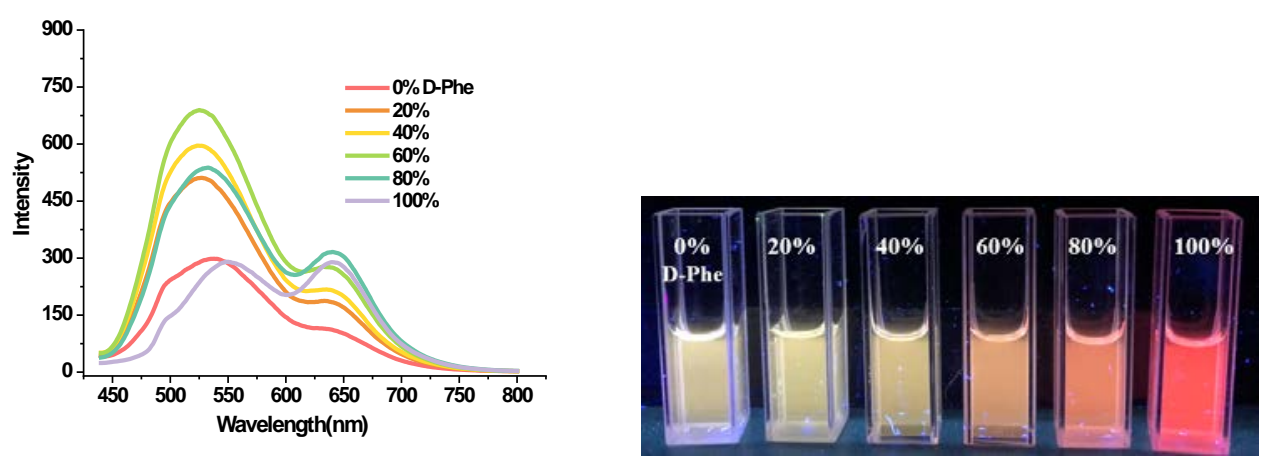

Figure S23(c). (R)-5:(S)-4 = 1: $5.7(3 \mu \mathrm{M}+17 \mu \mathrm{M})$. The fluorescence spectra and visualization analysis of $(R)-5\left(3 \mu \mathrm{M}\right.$ in DMSO) $+(S)-4(17 \mu \mathrm{M}$ in $\mathrm{MeOH})+\mathrm{Zn}^{2+}$ (2 equiv, 40 $\mu \mathrm{M})$ with different enantiomeric composition of Phe (100 eq) in $50 \mathrm{mM}$ HEPES. The fluorescence spectra were recorded at room temperature after mixing for $3 \mathrm{~h}(\lambda \mathrm{exc}=420 \mathrm{~nm}$, slits:5/5 nm).
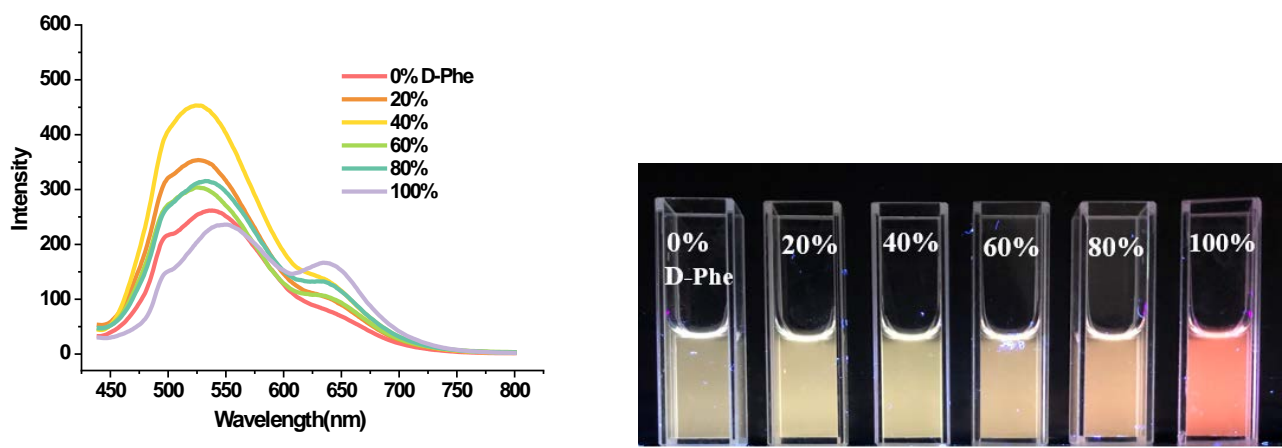

Figure S23(d). $(R)-\mathbf{5}:(S)-\mathbf{4}=1: 9 \quad(2 \mu \mathrm{M}+18 \mu \mathrm{M})$. The fluorescence spectra and visualization analysis of $(R)-5\left(2 \mu \mathrm{M}\right.$ in DMSO) $+(S)-4(18 \mu \mathrm{M}$ in $\mathrm{MeOH})+\mathrm{Zn}^{2+}$ (2 equiv, 40 $\mu \mathrm{M}$ ) with different enantiomeric composition of Phe (100 equiv) in $50 \mathrm{mM}$ HEPES. The fluorescence spectra were recorded at room temperature after mixing for $3 \mathrm{~h}$ ( $\lambda$ exc $=420 \mathrm{~nm}$, slits:5/5 nm).
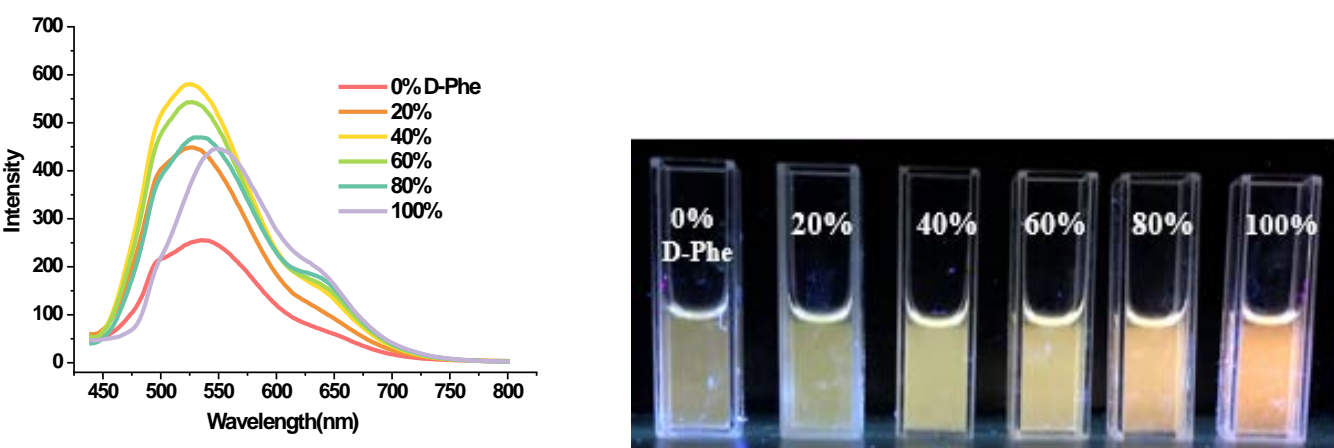
5.7 Visual quantification of the enantiomeric composition of tryptophane

Figure S24. The fluorescence spectra and visualization test of $(R)-\mathbf{5}+(S)-\mathbf{4}$ (at various ratios) $+\mathrm{Zn}^{2+}$ (2 equiv, $40 \mu \mathrm{M}$ ) with 100 equiv $D$-Trp or 100 equiv $L$-Trp in $50 \mathrm{mM}$ HEPES. The fluorescence spectra were recorded at room temperature after mixing for $3 \mathrm{~h}(\lambda \mathrm{exc}=420 \mathrm{~nm}$, slits:5/5 nm).
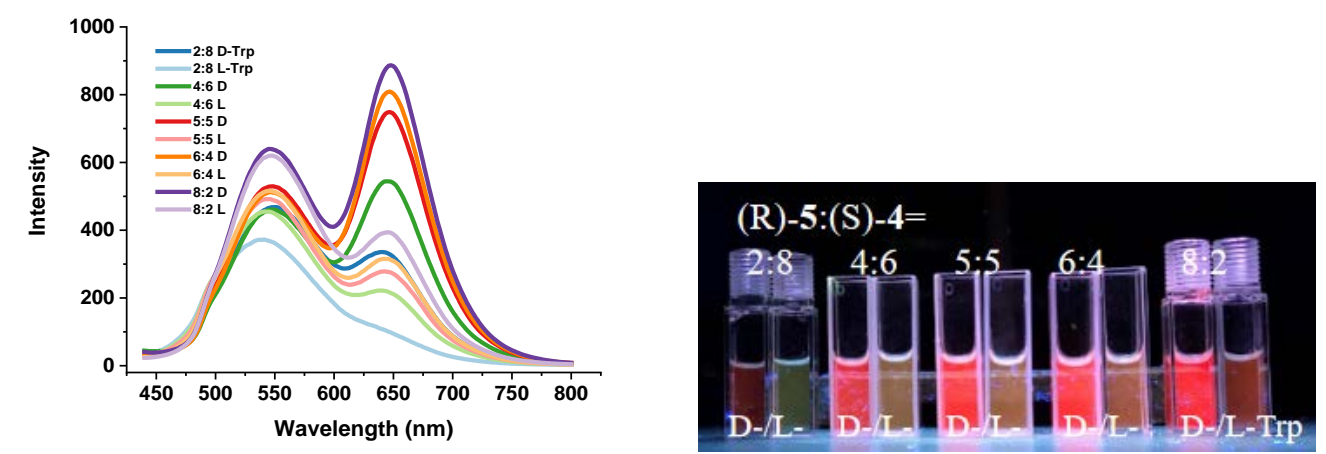

Figure S24(a). $\quad(R)-5:(S)-4=1: 1 \quad(10 \mu \mathrm{M}+10 \mu \mathrm{M})$. The fluorescence spectra and visualization analysis of $(R)-5\left(10 \mu \mathrm{M}\right.$ in DMSO) $+(S)-4(10 \mu \mathrm{M}$ in $\mathrm{MeOH})+\mathrm{Zn}^{2+}$ (2 equiv, $40 \mu \mathrm{M}$ ) with different enantiomeric composition of Trp (100 equiv) in $50 \mathrm{mM}$ HEPES. The fluorescence spectra were recorded at room temperature after mixing for $3 \mathrm{~h}(\lambda \mathrm{exc}=420 \mathrm{~nm}$, slits:5/5 nm).
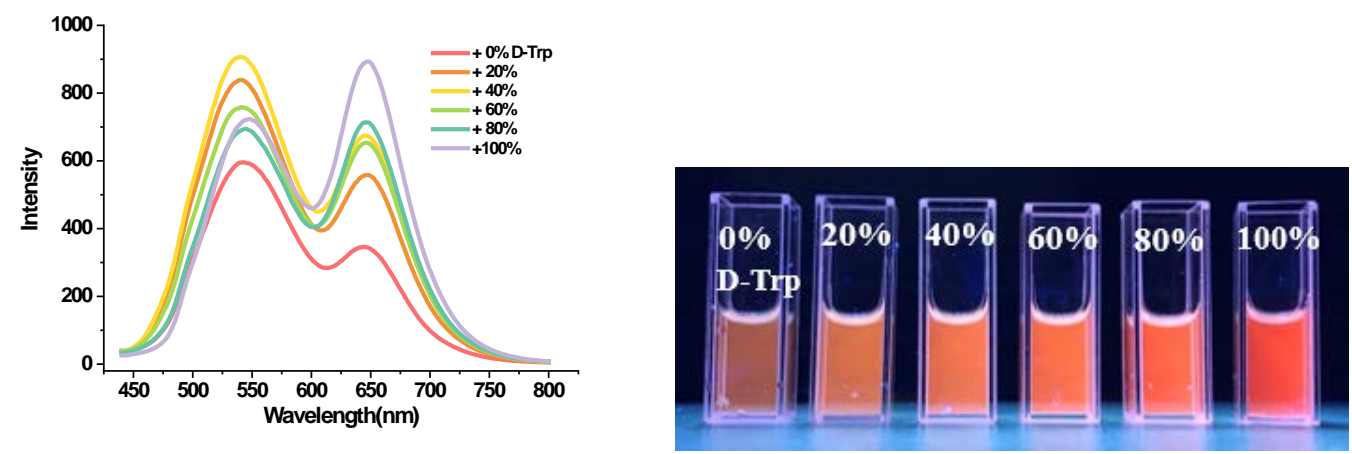

Figure S24(b). $\quad(R)-\mathbf{5}:(S)-4=1: 4 \quad(4 \mu \mathrm{M}+16 \mu \mathrm{M})$. The fluorescence spectra and visualization analysis of $(R)-5\left(4 \mu \mathrm{M}\right.$ in DMSO) $+(S)-4(16 \mu \mathrm{M}$ in $\mathrm{MeOH})+\mathrm{Zn}^{2+}$ (2 equiv, 40 $\mu \mathrm{M})$ with different enantiomeric composition of Trp (100 equiv) in $50 \mathrm{mM}$ HEPES. The fluorescence spectra were recorded at room temperature after mixing for $3 \mathrm{~h}(\lambda \mathrm{exc}=420 \mathrm{~nm}$, slits:5/5 nm).
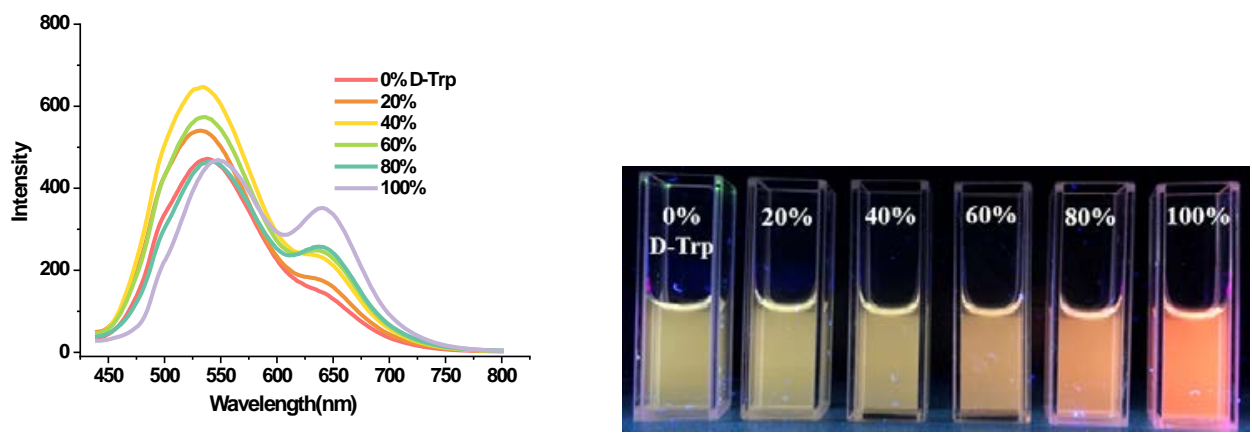
Figure S24(c). $\quad(R)-5:(S)-4=1: 5.7 \quad(3 \mu \mathrm{M}+17 \mu \mathrm{M})$. The fluorescence spectra and visualization analysis of $(R)-5(3 \mu \mathrm{M}$ in DMSO $)+(S)-\mathbf{4}(17 \mu \mathrm{M}$ in $\mathrm{MeOH})+\mathrm{Zn}^{2+}$ (2 equiv, 40 $\mu \mathrm{M})$ with different enantiomeric composition of Trp (100 equiv) in $50 \mathrm{mM}$ HEPES. The fluorescence spectra were recorded at room temperature after mixing for $3 \mathrm{~h}(\lambda \mathrm{exc}=420 \mathrm{~nm}$, slits:5/5 nm).
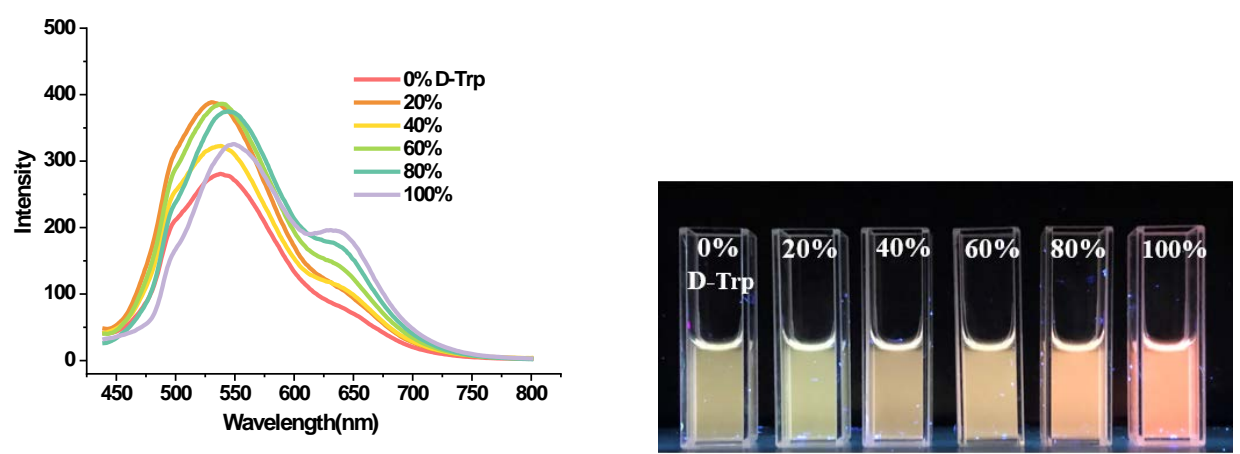

Figure S24(d). $\quad(R)-\mathbf{5 : ( S ) - 4}=1: 9 \quad(2 \mu \mathrm{M}+18 \mu \mathrm{M})$. The fluorescence spectra and visualization analysis of $(R)-5\left(2 \mu \mathrm{M}\right.$ in DMSO) $+(S)-4(18 \mu \mathrm{M}$ in $\mathrm{MeOH})+\mathrm{Zn}^{2+}$ (2 equiv, 40 $\mu \mathrm{M})$ with different enantiomeric composition of Trp (100 equiv) in $50 \mathrm{mM}$ HEPES. The fluorescence spectra were recorded at room temperature after mixing for $3 \mathrm{~h}(\lambda \mathrm{exc}=420 \mathrm{~nm}$, slits:5/5 nm).
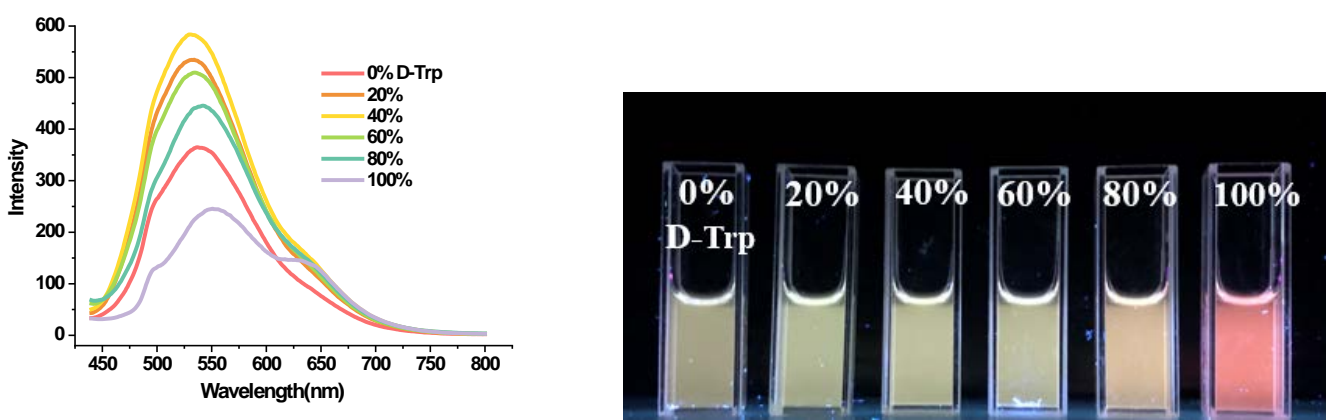


\section{UV-Vis spectra, NMR and Mass spectroscopic studies of the reactions}

Figure S25. (R)-5 (2 mM) +2 equiv $\mathrm{Zn}(\mathrm{OAc})_{2}+2$ equiv methionine was allowed to stand at room temperature for $3 \mathrm{~h}$, and then diluted to $20 \mu \mathrm{M}$ with HEPES before UV-Vis measurements.

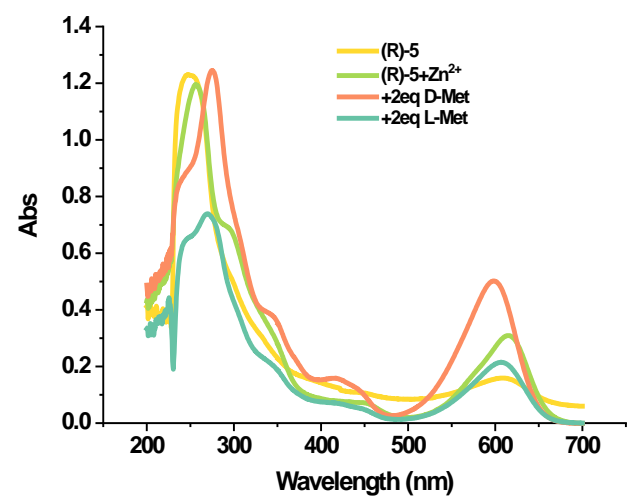

Figure S26. Fluorescence spectra of the above samples used for UV-Vis measurements.

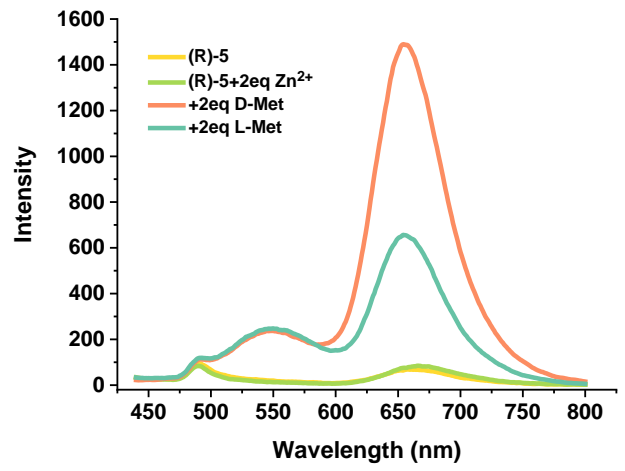


Figure S27. ${ }^{1} \mathrm{H}$ NMR $(600 \mathrm{MHz})$ spectra of $(R)-5(4 \mathrm{mM})+\mathrm{ZnBr}_{2}$ (2 equiv) with $D$-Met or $L$-Met in DMSO-d $\mathrm{d}_{6}$ : HEPES buffer prepared from $\mathrm{D}_{2} \mathrm{O}(3: 1 \mathrm{v}: \mathrm{v})$ (The ${ }^{1} \mathrm{H}$ NMR spectra were taken after the solution was allowed to stand at room temperature for $3 \mathrm{~h}$. HEPES buffer: 50 $\mathrm{mM}$ at $\mathrm{pD}=7.4$ made with $\mathrm{D}_{2} \mathrm{O}$ ).

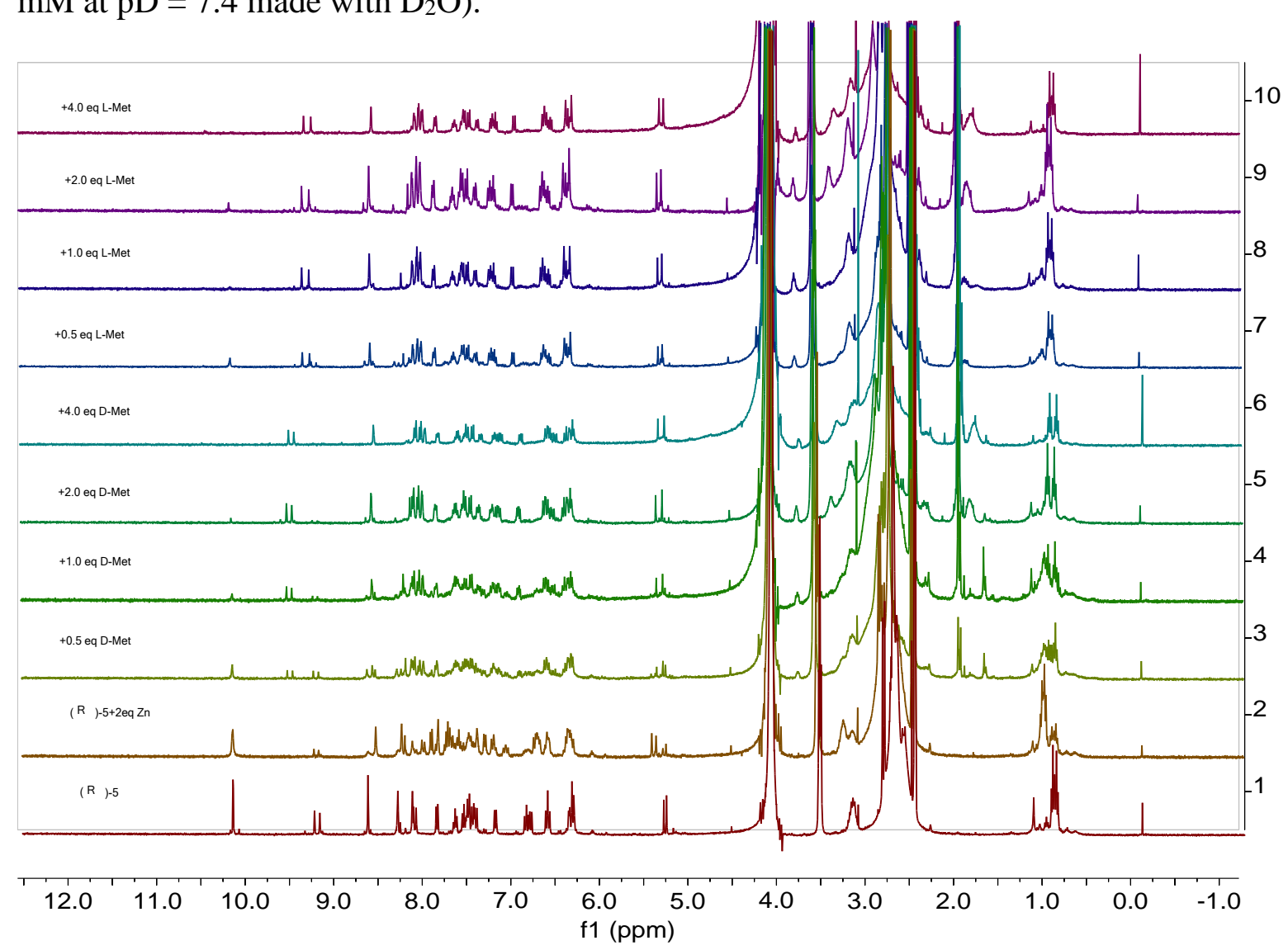

Figure S28. TOF mass spectra of $(R)-5\left(2.0 \times 10^{-5} \mathrm{M}\right)+\mathrm{ZnBr}_{2}$ (2 equiv) + D-Met (2 equiv). ESI+:

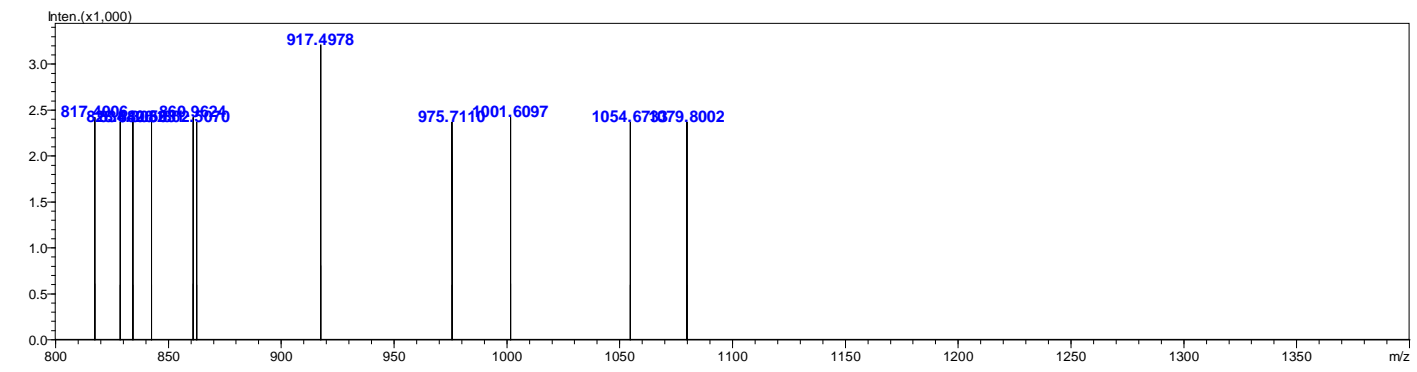

ESI-:

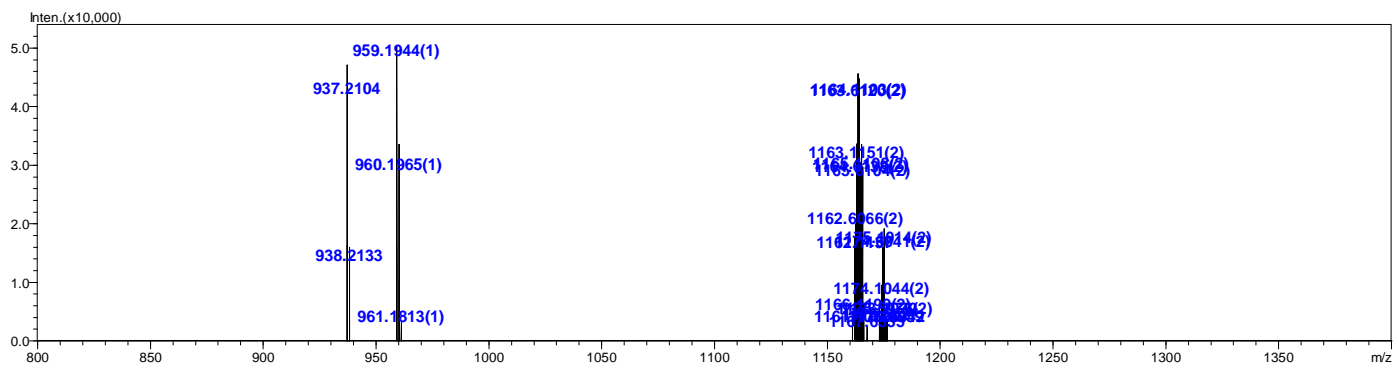




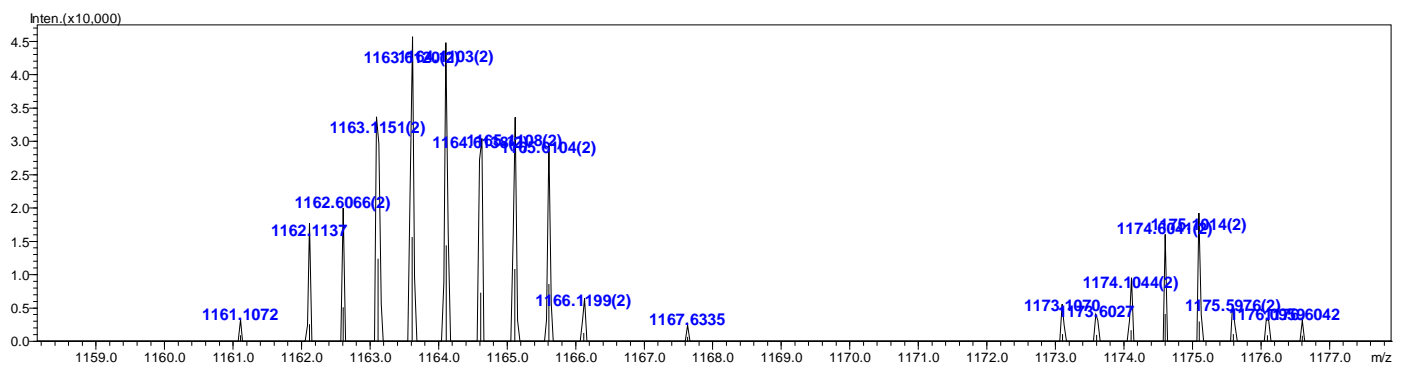

Figure S29. TOF mass spectra of $(R)-5\left(2.0 \times 10^{-5} \mathrm{M}\right)+\mathrm{ZnBr}_{2}$ (2 equiv) + L-Met (2 equiv).

\section{ESI+}

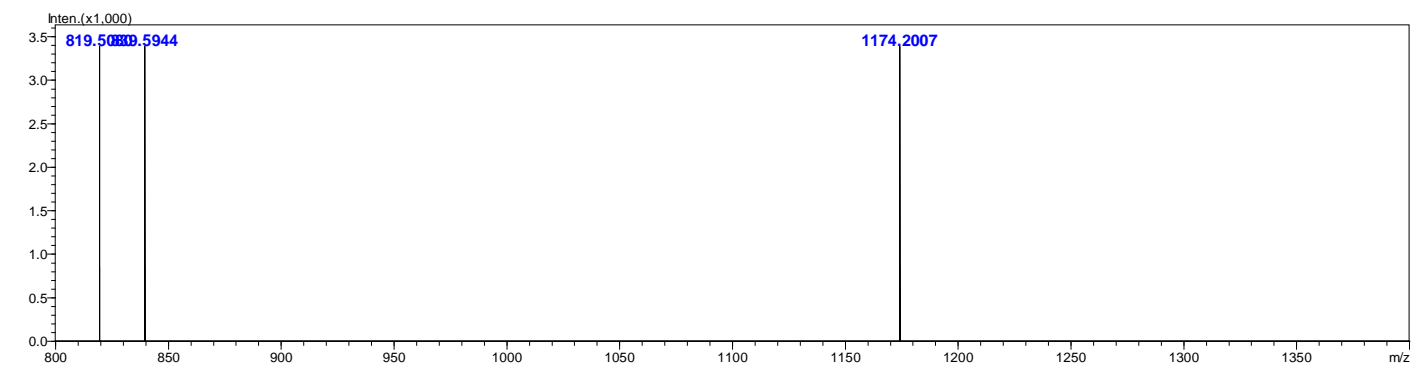

\section{ESI-}
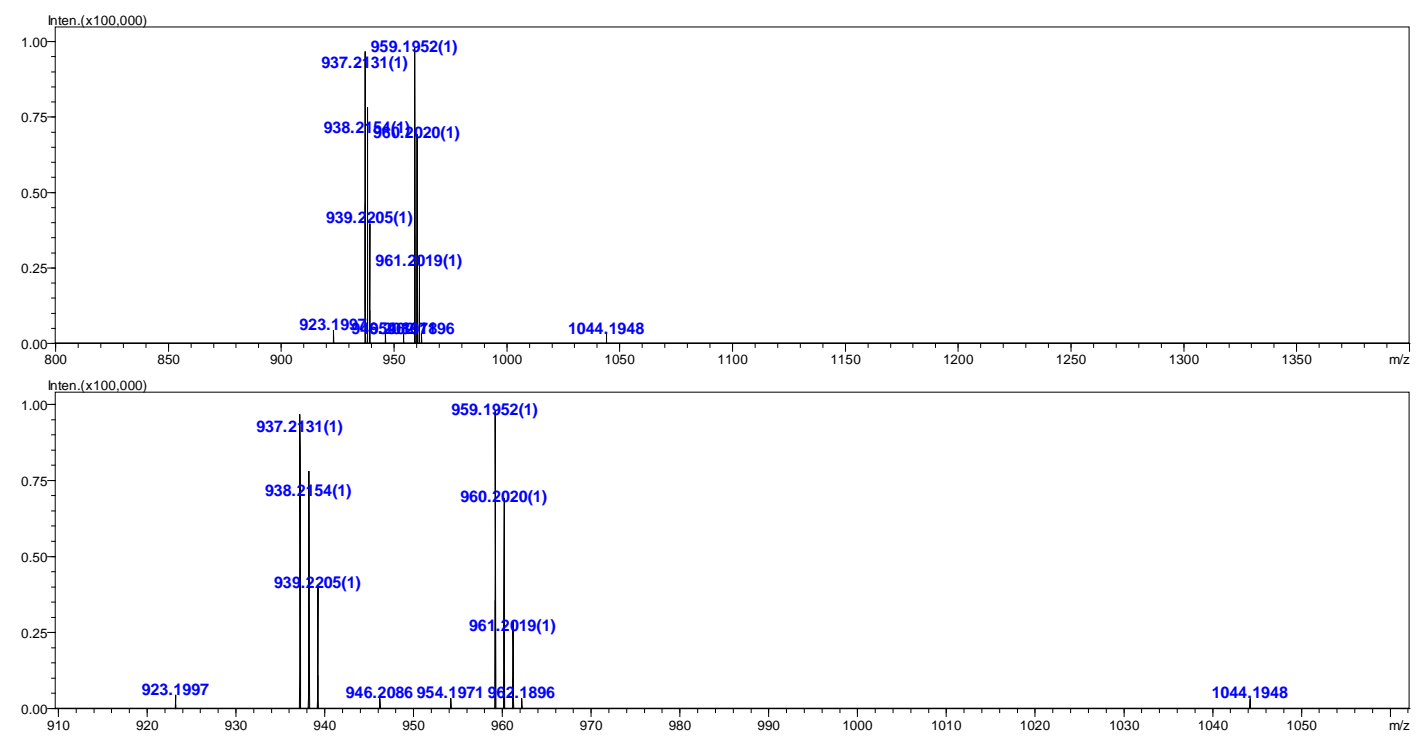